\title{
AirCore-HR: a high-resolution column sampling to enhance the vertical description of $\mathrm{CH}_{4}$ and $\mathrm{CO}_{2}$
}

\author{
Olivier Membrive $^{1,2}$, Cyril Crevoisier $^{1}$, Colm Sweeney $^{3,4}$, François Danis $^{1}$, Albert Hertzog ${ }^{1}$, Andreas Engel $^{5}$, \\ Harald Bönisch ${ }^{5}$, and Laurence Picon ${ }^{2}$ \\ ${ }^{1}$ Laboratoire de Météorologie Dynamique, IPSL, CNRS, École Polytechnique, Université Paris-Saclay, \\ 91128, Palaiseau, France \\ ${ }^{2}$ Laboratoire de Météorologie Dynamique, IPSL, CNRS, UPMC Université Paris 06, Sorbonne Universités, 75252, Paris, \\ France \\ ${ }^{3}$ Cooperative Institute for Research in Environmental Sciences, University of Colorado, Boulder, USA \\ ${ }^{4}$ National Oceanic and Atmospheric Administration, Earth System Research Laboratory, NOAA/ESRL, Boulder, Colorado, \\ USA \\ ${ }^{5}$ Institute for Atmospheric and Environmental Sciences, University of Frankfurt, Frankfurt, Germany
}

Correspondence to: Olivier Membrive (olivier.membrive@1md.polytechnique.fr)

Received: 15 July 2016 - Discussion started: 26 September 2016

Revised: 8 February 2017 - Accepted: 7 April 2017 - Published: 12 June 2017

\begin{abstract}
An original and innovative sampling system called AirCore was presented by NOAA in 2010 (Karion et al., 2010). It consists of a long $(>100 \mathrm{~m})$ and narrow $(<1 \mathrm{~cm})$ stainless steel tube that can retain a profile of atmospheric air. The captured air sample has then to be analyzed with a gas analyzer for trace mole fraction. In this study, we introduce a new AirCore aiming to improve resolution along the vertical with the objectives to (i) better capture the vertical distribution of $\mathrm{CO}_{2}$ and $\mathrm{CH}_{4}$, (ii) provide a tool to compare AirCores and validate the estimated vertical resolution achieved by AirCores. This (high-resolution) AirCore-HR consists of a $300 \mathrm{~m}$ tube, combining $200 \mathrm{~m}$ of $0.125 \mathrm{in}$. (3.175 mm) tube and a $100 \mathrm{~m}$ of $0.25 \mathrm{in} .(6.35 \mathrm{~mm})$ tube. This new configuration allows us to achieve a vertical resolution of $300 \mathrm{~m}$ up to $15 \mathrm{~km}$ and better than $500 \mathrm{~m}$ up to $22 \mathrm{~km}$ (if analysis of the retained sample is performed within $3 \mathrm{~h}$ ). The AirCore-HR was flown for the first time during the annual StratoScience campaign from CNES in August 2014 from Timmins (Ontario, Canada). High-resolution vertical profiles of $\mathrm{CO}_{2}$ and $\mathrm{CH}_{4}$ up to $25 \mathrm{~km}$ were successfully retrieved. These profiles revealed well-defined transport structures in the troposphere (also seen in CAMS-ECMWF high-resolution forecasts of $\mathrm{CO}_{2}$ and $\mathrm{CH}_{4}$ profiles) and captured the decrease of $\mathrm{CO}_{2}$ and $\mathrm{CH}_{4}$ in the stratosphere. The multi-instrument gondola also carried two other low-resolution AirCore-GUF that al-
\end{abstract}

lowed us to perform direct comparisons and study the underlying processing method used to convert the sample of air to greenhouse gases vertical profiles. In particular, degrading the AirCore-HR derived profiles to the low resolution of AirCore-GUF yields an excellent match between both sets of $\mathrm{CH}_{4}$ profiles and shows a good consistency in terms of vertical structures. This fully validates the theoretical vertical resolution achievable by AirCores. Concerning $\mathrm{CO}_{2}$ although a good agreement is found in terms of vertical structure, the comparison between the various AirCores yields a large and variable bias (up to almost $3 \mathrm{ppm}$ in some parts of the profiles). The reasons of this bias, possibly related to the drying agent used to dry the air, are still being investigated. Finally, the uncertainties associated with the measurements are assessed, yielding an average uncertainty below $3 \mathrm{ppb}$ for $\mathrm{CH}_{4}$ and $0.25 \mathrm{ppm}$ for $\mathrm{CO}_{2}$ with the major source of uncertainty coming from the potential loss of air sample on the ground and the choice of the starting and ending point of the collected air sample inside the tube. In an ideal case where the sample would be fully retained, it would be possible to know precisely the pressure at which air was sampled last and thus to improve the overall uncertainty to about $0.1 \mathrm{ppm}$ for $\mathrm{CO}_{2}$ and $2 \mathrm{ppb}$ for $\mathrm{CH}_{4}$. 


\section{Introduction}

Understanding the global atmospheric budget of the two major greenhouse gases (GHG) emitted by human activities, carbon dioxide $\left(\mathrm{CO}_{2}\right)$ and methane $\left(\mathrm{CH}_{4}\right)$, is essential for predicting their future concentration levels. To that end, several efforts have been dedicated to improving the monitoring capabilities of these gases. Under coordination by the World Meteorological Organization (WMO), a global atmospheric $\mathrm{CO}_{2}$ and $\mathrm{CH}_{4}$ monitoring network of surface-based stations has been established (GCOS, 2011) to provide continuous information on their atmospheric concentrations. Although essential to infer surface fluxes, these surface measurements are sparse and lack information pertaining to the vertical structure of the atmospheric $\mathrm{CO}_{2}$ and $\mathrm{CH}_{4}$. In order to improve spatial coverage, several satellite-based missions have been developed to monitor greenhouse gases from space. Observations in the shortwave infrared (SWIR) enable the retrieval total atmospheric columns, during daytime and mostly over land. SWIR missions include the Scanning Imaging Absorption Spectrometer for Atmospheric Chartography (SCIAMACHY) spanning 2003-2012 (Frankenberg et al., 2011; Wecht et al., 2014), the Greenhouse Gases Observing Satellite (GOSAT) since 2009 (Hamazaki et al., 2007; Butz et al., 2011) and more recently the Orbiting Carbon Observatory (OCO-2) for $\mathrm{CO}_{2}$ only (Crisp et al., 2004; Hammerling et al., 2012). Observations of terrestrial radiation in the thermal infrared (TIR) provide information mostly on mid-tropospheric columns, by day and night, over land and sea. Missions include the Atmospheric Infrared Sounder (AIRS) since 2002 (Crevoisier et al., 2003; Xiong et al., 2010), the Tropospheric Emission Spectrometer (TES) from 2004 to 2011 (Worden et al., 2012) and the Infrared Atmospheric Sounding Interferometer (IASI) since 2007 (Crevoisier et al., 2009a, b, 2013; Xiong et al., 2013). Vertical profiles of $\mathrm{CO}_{2}$ and $\mathrm{CH}_{4}$ are also available from limb measurements such as from the Atmospheric Chemistry Experiment (ACE-FTS; Foucher et al., 2011). These satellite-based vertical profiles mainly cover the upper troposphere and low stratosphere (UTLS) with a low vertical resolution.

One of the main challenges for any satellite-based measurements is data evaluation and the comparability to WMO standards. To that end the Total Column Observing Network (TCCON; Wunch et al., 2010) has been established. It consists of a network of upward-looking Fourier transform spectrometers (FTS) and has been widely used to evaluate retrievals of total columns from SWIR space missions (e.g., Houweling et al., 2014). TCCON provides column-averaged retrievals that do not have any vertical resolution and also require independent evaluation of the data.

Precise and regular vertical profile measurements from the surface to above the tropopause are currently missing to evaluate total or partial columns of GHG retrieved either from the ground or from space and to tie them to the calibrated measurements of the WMO.
Several aircraft missions contribute vertical information with regular measurements along commercial airlines such as the CONTRAIL project (Machida et al., 2008) and the CARIBIC project (Schuck et al., 2009). Other, less regular aircraft campaigns are also dedicated to study GHG at a local scale (Zhang et al., 2014; Chen et al., 2010; Karion et al., 2013; Crevoisier et al., 2006, 2010; Sweeney et al., 2015) or from pole to pole such as the HIPPO project (Wofsy, 2011). Such vertical profiles are usually limited to $12 \mathrm{~km}$.

To overcome this limitation, several instruments to measure $\mathrm{CO}_{2}$ and $\mathrm{CH}_{4}$ profiles have been developed for deployment on high-altitude balloons. Commonly used techniques include FTS measurements such as the Michelson Interferometer for Passive Atmospheric Sounding (MIPAS; Oelhaf et al., 1991), cryogenic samplers (e.g., Schmidt and Khedim, 1991; Engel et al., 2008) to capture air in flasks at different altitudes along the balloon flight to be analyzed at a later stage, and laser-diode spectrometers such as the Spectromètre Infra Rouge pour l'Étude de l'Atmosphère par Diode Laser Embarquées (SPIRALE; Moreau et al., 2005) or Pico-SDLA instruments (Durry et al., 2004; Ghysels et al., 2011; Joly et al., 2007). All these instruments must be flown on heavy balloon-borne platforms. They can thus not be flown on a regular basis.

In this context, an original and innovative atmospheric sampling system called AirCore has been developed at the National Oceanic and Atmospheric Administration Earth System Research Laboratory (NOAA/ESRL; Karion et al., 2010) from an idea originally developed and patented by Pieter Tans (Tans, 2009). It consists of a long and thin stainless steel tube shaped in the form of a coil which can sample the surrounding atmosphere and preserve a profile. This new system allows balloon measurements of GHG vertical profiles from the surface up to approximately $30 \mathrm{~km}$. The vertical resolution is ultimately determined by the length and diameter of the tubes.

Since the development of the first AirCore (Karion et al., 2010), new and lighter AirCores have been developed at NOAA, Groningen University and Goethe University Frankfurt. These lighter AirCores capture a smaller volume of air, leading to a slight decrease in the achievable vertical resolution. This paper focuses on the development of an AirCore that allows the retrieval of profiles of GHG with a higher resolution along the vertical, with the following objectives: (i) to better capture the vertical distribution of atmospheric $\mathrm{CO}_{2}$ and $\mathrm{CH}_{4}$ in the troposphere, UTLS and stratospheric regions; and (ii) to provide a tool to compare low-resolution AirCores and validate the theoretical resolution achievable by AirCores.

The design of this new high-resolution AirCore, named AirCore-HR, is presented in Sect. 2 together with the description of the experimental settings and processing method. Section 3 describes the first flight of AirCore-HR. Section 4 describes the resulting $\mathrm{CO}_{2}$ and $\mathrm{CH}_{4}$ high-resolution profiles and associated uncertainties and compares high- and low- 


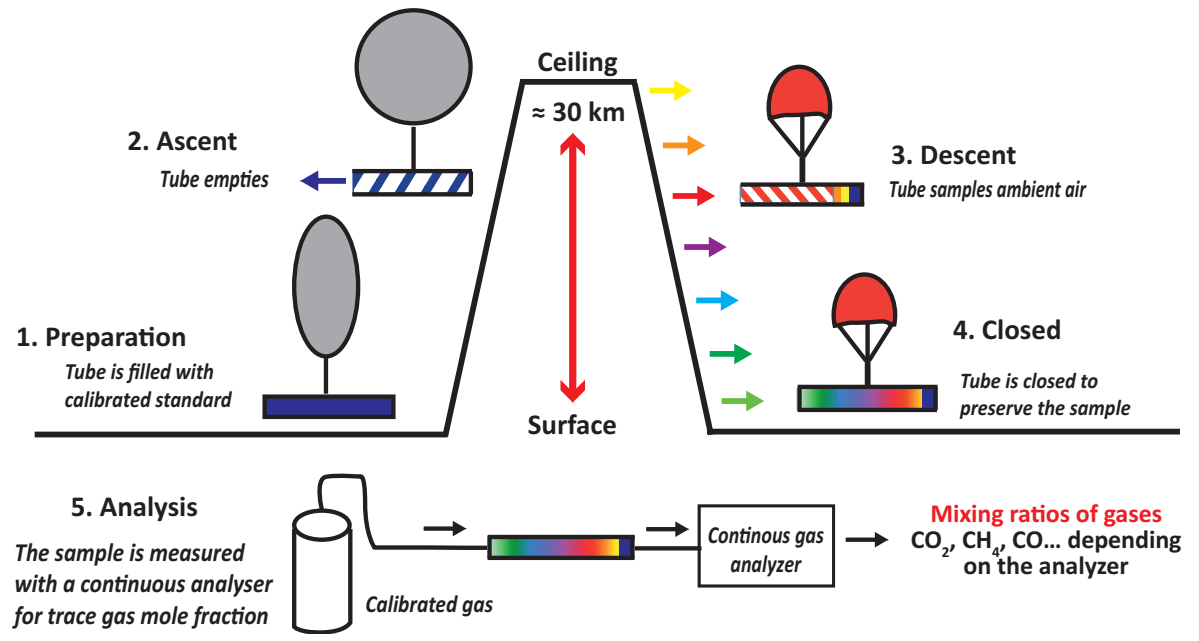

Figure 1. Schematic description of the five steps of the AirCore sampling method.

resolution profiles retrieved from two AirCores. Section 5 gives the conclusion.

\section{AirCore-HR design, experimental setup and processing method}

The general principle of an AirCore is illustrated in Fig. 1. First, in a preparation phase, the tube is filled with a calibrated gas standard. It is placed under a balloon with one end of the tube open and the other end closed. During the ascent phase, as the air in the tube equilibrates with ambient pressure, the initial fill gas evacuates. After reaching an upper limit, where only a small fraction of the initial fill gas remains in the tube, the AirCore starts a descent phase. During this phase, as it maintains pressure equilibrium along the descent, the tube samples the ambient air. On the ground, the tube is closed, retaining the sampled profile to be analyzed with an analyzer for trace gas mole fraction.

\subsection{Relation between AirCore design and vertical resolution}

AirCores can be designed in a variety of configurations that determine the vertical resolution that can be achieved with the instrument. The resolution directly depends on the molecular diffusion and shear flow diffusivity, otherwise known as Taylor dispersion, inside the tube (Karion et al., 2010). The two major criteria in designing an AirCore are thus: (i) keeping the tubes diameter sufficiently thin to have a laminar flow at the sampling flow rates; and (ii) constraining the total weight to fit the specific flight requirements of their carrier (weather balloons, stratospheric balloons, planes, etc.) while allowing for sampling of a sufficient amount of air for the planned analysis.

\subsubsection{Impact of diffusion and dispersion on the vertical resolution}

As described in Karion et al. (2010), at the flow rates of gas entering the AirCore during flight $(<235 \mathrm{sccm}$; standard cubic centimeters per minute) and during analysis (30 to $120 \mathrm{sccm}$ ) the flow in the AirCore-HR is expected to be laminar. The transition between laminar and turbulent flow can be evaluated thanks to the dimensionless Reynolds number (Reynolds, 1883). Taking into account the useful parameters to describe the tubing of an AirCore Reynolds number can be expressed as follows:

$R_{e}=\frac{Q d_{\text {in }}}{v \Sigma_{\text {in }}}$,

where $Q$ is the flow rate expressed in $\mathrm{m}^{3} \mathrm{~s}^{-1}, d_{\text {in }}$ the inner diameter in meters, $v$ cinematic viscosity $\left(\frac{\mu}{\rho}\right)$ in $\mathrm{m}^{2} \mathrm{~s}^{-1}$ and $\Sigma_{\text {in }}$ the surface of the inner disc of a section of the tube in $\mathrm{m}^{2}$.

Most of the AirCore configurations will have the following characteristics: (i) $v$, the cinematic viscosity of air $\left(15.6 \times 10^{-6}\right.$ at $\left.20^{\circ} \mathrm{C}\right)$; (ii) the inner diameter of the tube $\left(d_{\text {in }}=0.15\right.$ to $\left.1 \mathrm{~cm}\right)$; (iii) $\Sigma_{\text {in }}$, the surface of an inner disc of a section of the tube $2 \pi r_{\text {int }}^{2}$ with $r_{\text {in }}=0.075$ to $0.5 \mathrm{~cm}$; and (iv) the flow rate $Q \approx 0.7 \mathrm{~cm}^{3} \mathrm{~s}^{-1}$ during analysis (about $40 \mathrm{~cm}^{3} \mathrm{~min}^{-1}$ ) and possibly up to $250 \mathrm{~cm}^{3} \mathrm{~min}^{-1}$, which is equivalent to $\approx 4 \mathrm{~cm}^{3} \mathrm{~s}^{-1}$ during the fast descent phases.

Such values yield a number of Reynolds between

$1,36<R_{e}<8,5$.

In all circumstances the flow in an AirCore is thus laminar since $R_{e}$ is much inferior to 1750 (Peixinho and Mullin, 2006).

Diffusion and dispersion are considered neither during ascent while the tube empties nor during descent when the sam- 
pled pressure range varies continuously and repartition of the air along the AirCore thus evolves rapidly. It is only from the moment the total column is sampled and the final air repartition reached that the described model is used to calculate the vertical resolution (i.e., from the moment the tube is sealed with the captured sample until the end of the analysis).

At first, during a given storage time before the payload is recovered only molecular diffusion will affect the sample. As described in Karion et al. (2010) the root mean square of the distance of molecular travel is given by

$X_{\mathrm{rms}}=\sqrt{\left(2 D t_{\text {recovery }}\right)}$,

where $D$ is the molecular diffusivity of the different molecules in the surrounding gas. In air, at $20^{\circ} \mathrm{C}$ and $1000 \mathrm{hPa}, D$ is $0.16 \mathrm{~cm}^{2} \mathrm{~s}^{-1}$ for $\mathrm{CO}_{2}$, while for $\mathrm{CH}_{4}$ it is $0.23 \mathrm{~cm}^{2} \mathrm{~s}^{-1}$ (Massman, 1998). $t_{\text {recovery }}$ is the waiting time before analysis.

Then, during analysis, both molecular diffusion and the Taylor dispersion affecting the sample have to be accounted for. During this phase the root mean square of the distance of molecular travel is given by

$X_{\text {rms }}=\sqrt{\left(2 D_{\text {eff }} t_{\text {analysis }}\right)}$,

where $t_{\text {analysis }}$ is time needed for a parcel of the sampled air to reach the analyzer's cell and $D_{\text {eff }}$ is the effective diffusion coefficient combining molecular diffusion and Taylor dispersion given by

$D_{\text {eff }}=D+\frac{a^{2} \bar{V}^{2}}{48 D}$,

where $D$ is the molecular diffusivity of the different molecules in the surrounding gas, $a$ is the tube's inner radius, and $\bar{V}$ is the average velocity of the air inside the tube.

In addition to the effects of diffusion and dispersion, which are the main drivers of the resulting vertical resolution, the smearing effect of the cell of the analyzer during analysis has to be taken into account. The analyzer used in this study (Picarro cavity ring-down spectrometer (CRDS); G2310) pulls the sample at $110 \mathrm{sccm}$ and measuring at $0.5 \mathrm{~Hz}$ makes one measurement every $3.7 \mathrm{scc}$ (standard cubic centimeters). The analyzer cell has a standard volume of approximately $6 \mathrm{scc}$, since it is $35 \mathrm{cc}$ in volume, but is maintained at $187 \mathrm{hPa}$ (140 torr) and $45^{\circ} \mathrm{C}$. The volume of the cell needs to be flushed about three times for the air to be completely renewed (Stowasser et al., 2014).

To account for mixing in the volume of the cell of the analyzer, a Gaussian function characterized by the following standard deviation $\sigma_{\text {cell }}$ is considered:

$\sigma_{\text {cell }}=\frac{1}{2} \frac{V_{\text {cell }}}{\Sigma_{\text {in }}}=\frac{1}{2} l_{\text {tube }}$, where $V_{\text {cell }}$ represents the volume of the cell, $\Sigma_{\text {in }}$ the inner surface of a tube $\left(\pi r_{\text {in }}^{2}\right)$ and $l_{\text {tube }}$ the AirCore length required to store the volume of the cell. A Gaussian function characterized by this standard deviation allows us to show that mixing impacts a distance in the AirCore where almost 3 times the volume required to fill the cell is stored.

As all mixing effects can be considered Gaussian, the total distance of diffusion $X_{\text {rms }}$ to be considered is given by

$X_{\text {rms }}=\sqrt{2 D t_{\text {recovery }}+2 D_{\text {eff }} t_{\text {analysis }}+\left(\frac{1}{2} l_{\text {tube }}\right)^{2}}$.

Using Eq. (7) and knowing that air is distributed in the AirCore as a linear function of total pressure column sampled, it is possible to evaluate the pressure range affected by mixing related to diffusion and dispersion. The factor of 2 in front of $\mathrm{X}_{\mathrm{rms}}$ comes from accounting for diffusion in both directions.

$\Delta P=P_{\max } \frac{2 X_{\mathrm{rms}}}{L}$,

where $\Delta P$ represents the effective resolution and $P_{\max }$ the pressure at the surface when the coil is closed. $L$ is the total length of the AirCore. In the case of two tubes or more, $\Delta P$ can be calculated independently for each tube.

Using a standard atmosphere temperature profile it is then possible using the hydrostatic law to associate the atmospheric pressure with a given altitude. In order to best represent the latitudes at which the AirCores are to be deployed, we used the average temperature profile of the representative TIGR (Thermodynamic Initial Guess Retrieval) dataset (Chedin et al., 1985, available at http://ara.abct.lmd. polytechnique.fr/index.php?page=tigr) for midlatitudes.

\subsubsection{Aiming for a high-resolution AirCore}

To appreciate the value of the AirCore-HR it is important to understand the factors that determine the resolution of an AirCore. The first factor is the sample cell of the analyzer that will limit the number of independent measurements over the sampled volume. The second factor is the diffusion distance (explained above) which, depending on the diameter of the tube and the lag between when air was sampled and when it is analyzed, will eventually limit the sampling resolution of the AirCore.

At midlatitudes, air sampled over a $10 \mathrm{hPa}$ descent between 20 and $30 \mathrm{hPa}$ represents about $3 \mathrm{~km}$ of vertical distance whereas air sampled over a $10 \mathrm{hPa}$ descent between 450 and $460 \mathrm{hPa}$ represents about $200 \mathrm{~m}$ of vertical distance. This has a direct consequence for the observation of the stratosphere, for which the sampled air needs to be preserved while sampling as much of it as possible. This can be achieved by combining sections of tubes of different diameters. A given volume of air is indeed affected differently when stored in a section with a smaller diameter: although diffusion remains the same, the distance of travel for a molecule to impact an equivalent volume increases. Therefore, using at least two 


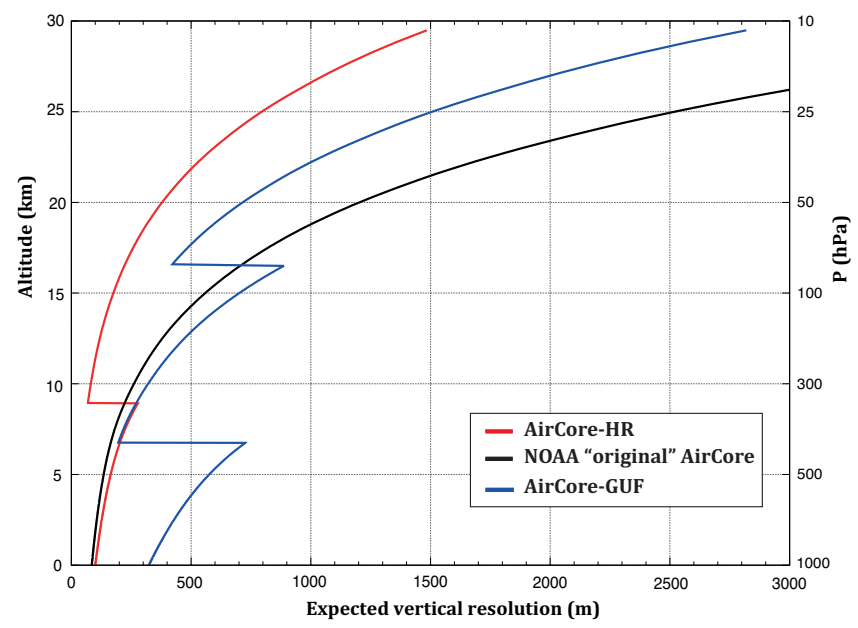

Figure 2. Comparison of the vertical resolution that can be expected with different AirCores for $\mathrm{CO}_{2}$ measurements after $3 \mathrm{~h}$ storage time before analysis: AirCore-HR (red), the original NOAA AirCore (black) and AirCore-GUF (blue).

tubes, one characterized by a small diameter at the end that remains closed and one characterized by a larger diameter at the end that remains open, allows us to keep a high resolution for the stratosphere (by storing the stratospheric part of the sampled profile in the tube with the smallest diameter) while still sampling a consequent volume of air thanks to the larger tube. To maximize the total volume of the AirCore-HR and limit the impact of the diffusion distance, the AirCore-HR was designed with tubes of two different diameters.

Figure 2 illustrates a comparison of the vertical resolution of $\mathrm{CO}_{2}$ measurements that can be expected for air sampled with different AirCores (for an analysis performed at $38.5 \mathrm{sccm}$, with a surface pressure $P_{\max }$ of $1013.25 \mathrm{hPa}$ and a given storage time of $3 \mathrm{~h}$ ). The resolution achievable with the first AirCore designed by NOAA (Karion et al., 2010) is shown in black. After $3 \mathrm{~h}$ of waiting time before analysis, it is possible to achieve a vertical resolution of $250 \mathrm{~m}$ at $10 \mathrm{~km}$ and $1.2 \mathrm{~km}$ at $20 \mathrm{~km}$.

In order to achieve a higher resolution along the whole atmospheric column, a design of a $300 \mathrm{~m}$ tube consisting of a $200 \mathrm{~m}$ of $0.125 \mathrm{in} .(3.175 \mathrm{~mm})$ tube and a $100 \mathrm{~m}$ of $0.25 \mathrm{in}$. $(6.35 \mathrm{~mm})$ tube linked together as one tube was selected for AirCore-HR. The increase in overall volume of the AirCoreHR allows a significant increase in resolution throughout the whole sampled air column (Fig. 2) as well as an increase of the overall weight. The resolution of the AirCore-HR for $\mathrm{CO}_{2}$ is estimated to be better than $300 \mathrm{~m}$ up to $15 \mathrm{~km}$ and better than $500 \mathrm{~m}$ up to $22 \mathrm{~km}$.

The resolution achievable by the lightweight AirCoreGUF designed and developed at Goethe University Frankfurt is also shown in Fig. 2. AirCore-GUF is a $100 \mathrm{~m}$ long combining three tubes: a $20 \mathrm{~m}$ long $8 \mathrm{~mm}$ tube, a $40 \mathrm{~m}$ long $4 \mathrm{~mm}$ tube and a $40 \mathrm{~m}$ long $2 \mathrm{~mm}$ tube. It has been designed
Table 1. Characteristics of the AirCore-HR.

\begin{tabular}{lrr}
\hline Tube & 0.25 in. tube & 0.125 in. tube \\
\hline Diameter (inches/cm) & $0.25 / 0.635$ & $0.125 / 0.3175$ \\
Width (inches/cm) & $0.02 / 0.0508$ & $0.02 / 0.0508$ \\
Inner diameter (inches/cm) & $0.21 / 0.5334$ & $0.085 / 02159$ \\
Length (m) & 100 & 200 \\
Volume $\left(\mathrm{cm}^{3}\right)$ & 2235 & 732 \\
Weight $(\mathrm{kg})$ & 7.48 & 6.82 \\
\hline \multicolumn{3}{c}{ Overall payload } \\
\hline \multicolumn{2}{c}{2967} \\
Overall payload volume $\left(\mathrm{cm}^{3}\right)$ \\
\hline
\end{tabular}

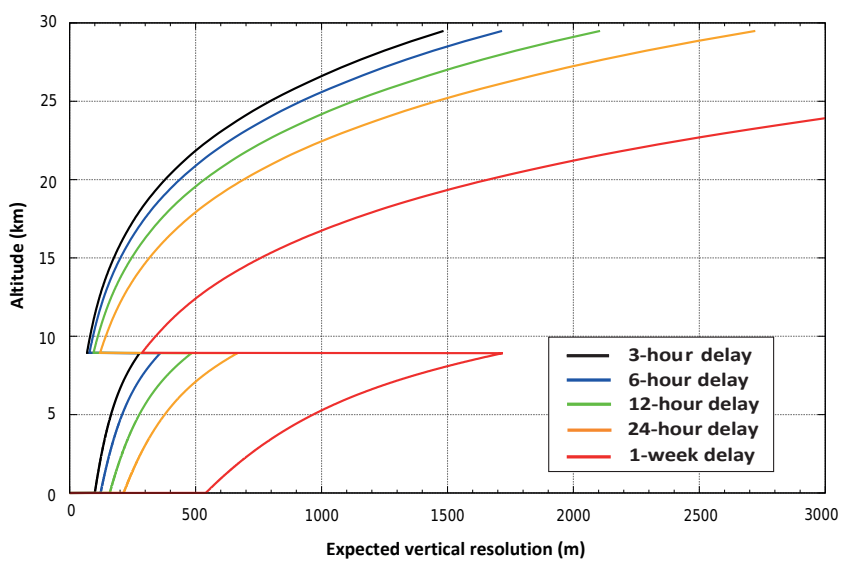

Figure 3. Impact of the time delay between landing and analysis on the expected vertical resolution of AirCore-HR, for a storage time of $3 \mathrm{~h}$ (black), $6 \mathrm{~h}$ (blue) and $12 \mathrm{~h}$ (green), $24 \mathrm{~h}$ (orange) and 1 week (red).

to be carried by meteorological balloons, resulting in compromises between weight and achievable resolution. Thanks to a third tube with thinner diameter, it has a good resolution in the stratosphere $(700 \mathrm{~m}$ at $20 \mathrm{~km})$.

The storage time between landing and analysis of the sample is a key factor influencing the vertical resolution. The resolutions plotted in Fig. 2 are for a storage time of $3 \mathrm{~h}$. Figure 3 shows the degradation of the resolution for various storage times of an air sample captured by the AirCore-HR. While a $6 \mathrm{~h}$ delay (blue plot) will still preserve a resolution better than $300 \mathrm{~m}$ up to $20 \mathrm{~km}$, waiting for $12 \mathrm{~h}$ after landing to perform the analysis will reduce the resolution to $500 \mathrm{~m}$ at $20 \mathrm{~km}$ (green plot). The impact of the delay on the achievable vertical resolution with the sampled profile is also presented for a $24 \mathrm{~h}$ delay (orange) and a 1-week delay (red). It is very clear from this figure that to avoid losing vertical resolution one of the challenges of using AirCores is to quickly recover the sample and perform the analysis. 


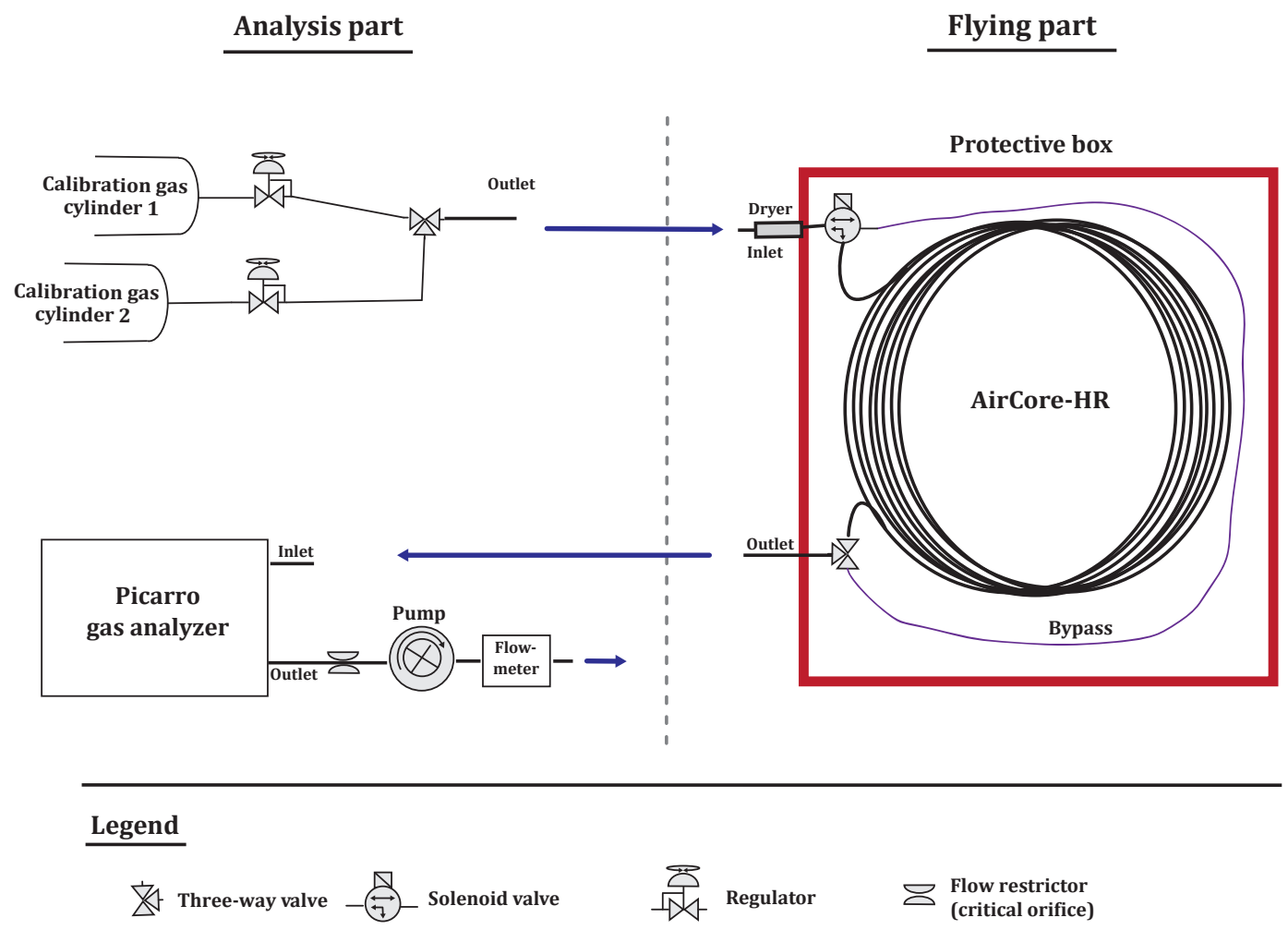

Figure 4. Overview of the AirCore-HR and analysis system.

\subsection{AirCore-HR experimental setup}

In order to obtain the vertical resolution shown in Fig. 2, the AirCore-HR comprises two tubes linked together as one, yielding an overall length of $300 \mathrm{~m}$, a weight of $14.3 \mathrm{~kg}$ and an inner volume of $2.967 \mathrm{~L}$. The detailed characteristics are given in Table 1. Both tubes have been treated by Restek, Inc., with Sulfinert ${ }^{\circledR}$ coating to reduce interactions of the sample with the walls.

The overall design is plotted in Fig. 4. Both sides of the coil are connected to three-way valves that allow ambient air to flow either through the AirCore-HR or through a bypass. This bypass consists in a $10 \mathrm{~cm}$ long, $0.0625 \mathrm{in} .(1.5875 \mathrm{~mm})$ diameter stainless steel tube that allows air to be pulled into the analyzer bypassing the AirCore-HR. During flight, in addition to this setting, a dryer consisting of a short length $(10 \mathrm{~cm})$ of stainless steel tube filled with fresh magnesium perchlorate is positioned at the open end of the tube (at the entrance of ambient air on the solenoid valve) to ensure that no moisture enters the tubes during sampling. The additional volume to the system is very small and represents less than $0.005 \%$ of the total volume (it is thus not considered in the calculation the vertical resolution; Sect. 2.1.1).

The AirCore-HR payload has been designed to fit into a polystyrene foam box. It is flown together with an electronic data package designed at LMD that collects meteorological data from a pressure sensor and three temperature probes and also controls the opening and closing of a solenoid valve at the open end of the AirCore. Temperature probes are placed along the AirCore in contact with various segments of the tube and allow monitoring the mean temperature along the coil during the flight. The pressure sensor is an absolute pressure sensor that measures the ambient air pressure during the flight.

\subsubsection{Laboratory testing}

Several tests were conducted in the laboratory under monitored conditions to evaluate the overall consistency of the AirCore-HR. In particular, the AirCore-HR has been tested for leaks at the junctions and at the valves used as closing points on each side of the AirCores. To test the preservation of the concentration of the sample, calibrated dry standard gases of two different values for both $\mathrm{CO}_{2}$ and $\mathrm{CH}_{4}$ are used. In repeated experiments under various conditions, it was noted that to reach the optimal Picarro CRDS precision at $0.5 \mathrm{~Hz}$ of $0.07 \mathrm{ppm}$ for $\mathrm{CO}_{2}$ and $0.5 \mathrm{ppb}$ for $\mathrm{CH}_{4}$ the tubes conducting the sampled air have to be perfectly dry. Therefore, the analysis line is systematically dried out by flowing dry air through the bypass. Water vapor concentration is closely monitored with the Picarro to be lower than $0.002 \%$ before conducting any tests with AirCore-HR. This method allows us to eliminate significant biases and to obtain mean measurements. 
Table 2. Values of the calibrated gas standards using NOAA's WMO scale reference. The air of the two reference tanks used in this study was measured at LSCE with a Picarro G2401 calibrated with a scale of six tanks from NOAA/ESRL. The table shows the reproducibility of the measurements and standard deviation over three measurements made during a 15-day period.

\begin{tabular}{l}
\hline Low-concentration standard \\
\hline $\mathrm{CO}_{2} 360.85 \mathrm{ppm} \pm 0.008 \mathrm{ppm}$ \\
$\mathrm{CH}_{4} 1726.95 \mathrm{ppb} \pm 0.163 \mathrm{ppb}$ \\
\hline High-concentration standard \\
\hline $\mathrm{CO}_{2} 401.31 \mathrm{ppm} \pm 0.004 \mathrm{ppm}$ \\
$\mathrm{CH}_{4} 1922.33 \mathrm{ppb} \pm 0.168 \mathrm{ppb}$ \\
\hline
\end{tabular}

\subsubsection{Atmospheric gas standards}

For testing and analysis of the AirCores, two calibrated gas standards are used. The cylinders are connected to a multiport valve, allowing selection of one of the gases.

The first standard is composed of high concentrations of $\mathrm{CO}_{2}$ and $\mathrm{CH}_{4}$ of, respectively, about $400 \mathrm{ppm}$ and $1900 \mathrm{ppb}$ and referred to as "high-concentration calibration standard". The other standard is composed of lower concentrations of $\mathrm{CO}_{2}$ and $\mathrm{CH}_{4}$ of about $360 \mathrm{ppm}$ and $1700 \mathrm{ppb}$, respectively, and referred to as "low-concentration standard". The gas cylinders have been calibrated on WMO scales at Laboratoire de Sciences du Climat et de l'Environnement (LSCE; courtesy of Michel Ramonet and Marc Delmotte) and the exact calibrated values of the standard can be found in Table 2 where $\mathrm{CO}_{2}$ concentrations are given on the WMOX2007 scale and $\mathrm{CH}_{4}$ concentrations are given on the NOAA-2004 scale.

\subsubsection{The Picarro CRDS analyzer}

All gas analyses of LMD AirCores were performed using one trace gas analyzer by Picarro, Inc., model G2310 (Crosson, 2008). The analyzer tightly controls the pressure and temperature in its measurement cell ( $187 \mathrm{hPa}\left(140\right.$ torr) and $\left.45^{\circ} \mathrm{C}\right)$, to achieve the above precision (see Sect. 2.2.1). The sample flow rate was controlled by a critical orifice placed at the outlet, limiting the flow at $38.5 \mathrm{sccm}$ during analysis.

\subsection{Processing method}

Upon recovery, the AirCore-HR is plugged into the prepared analysis system. It is first kept closed on both ends, allowing us to pull calibrated standards through the bypass into the analyzer. Once the values measured with the continuous analyzer are stabilized to the expected values for the calibration standard used as "push gas", the analysis of the air captured in the coil can start. This phase is very important to make sure that, after plugging the AirCore-HR in the system, the mixing ratio read by the Picarro is not contaminated
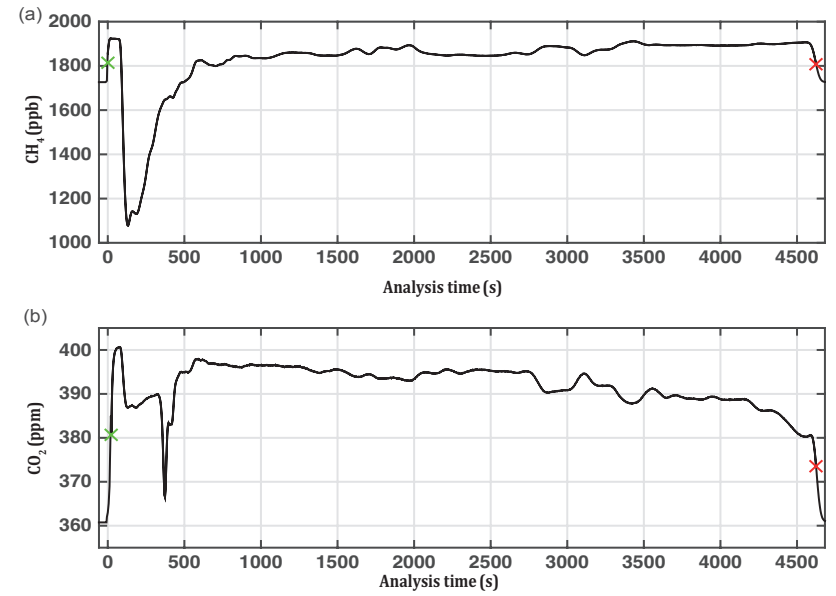

Figure 5. Picarro analysis of the AirCore-HR sample from the EdSStratéole flight on 29 August 2014. (a) $\mathrm{CH}_{4}$ mixing ratios as a function of the analysis time in seconds; (b) $\mathrm{CO}_{2}$ mixing ratios as a function of the analysis time in seconds. The selected starting point of the sample is marked with a green cross and marks the 0 of the analysis time; the selected ending point of the AirCore-HR sample is marked with a red cross.

by water vapor that could have entered the analysis chain. The collected sample is then analyzed by opening both ends simultaneously; the air is pulled from one end into the continuous analyzer and low-concentration calibration standard is pulled through the other end. The top of the profile with the remaining fill gas is pulled first into the analyzer.

The calibrated gas standards given in Table 2 allow replacing the values read by the Picarro onto the WMO scale. The high-concentration standard is used as fill gas to have a noticeable difference between fill gas and stratospheric air sample at the top of the profile. The low-concentration calibration standard is chosen to be used as push gas to have a noticeable difference of the mixing ratios compared with the expected values of $\mathrm{CO}_{2}$ and $\mathrm{CH}_{4}$ at the surface.

Several steps are required to accurately place the Picarro measurements on a vertical scale in order to retrieve the vertical profiles. The dry mole fraction of $\mathrm{CO}_{2}$ and $\mathrm{CH}_{4}$ provided by the Picarro are used. These are automatically corrected by the instrument for a combined effect of dilution and line broadening caused by water vapor (Chen et al., 2010; Rella et al., 2013). Then, in a first processing step, the measured mixing ratios are corrected for a bias from the Picarro measurement to the WMO scales. The correction is calculated thanks to the measurement of the calibrated standards by the Picarro at the time of analysis.

Figure 5 shows an example of $\mathrm{CO}_{2}$ and $\mathrm{CH}_{4}$ mixing ratios measured by the Picarro instrument during the StratoScience 2014 campaign. In order to extract the measurements corresponding to the sampled air, the top and the bottom of the profiles need to be defined. The top of the AirCore sample is considered to be at midpoint of the transition in concen- 
tration between the push gas and the remaining fill gas. This point corresponding to an estimated pressure of $0 \mathrm{hPa}$ in the tube is marked with a green cross in Fig. 5. The bottom of the profile is defined at midpoint on the transition of concentration between push gas and sampled air. It is marked with a red cross in Fig. 5.

As a first approach, it is assumed that the air entering the tube equilibrates the sample with ambient pressure and adjusts very quickly with the mean coil temperature. As the characteristics of the AirCore (length, diameter) do not change, ambient pressure and mean coil temperature are the two main factors that regulate the number of moles in the AirCore. Using the ideal gas law (Eq. 9), it is possible to calculate the number of moles captured in the tube all along the trajectory.

$P V=n R T \Leftrightarrow n=\frac{P V}{R T}$,

where $P$ is the ambient pressure, $V$ the inner volume of the AirCore, $n$ the fraction of moles, $R$ is the universal gas constant in $\mathrm{J} \mathrm{K}^{-1} \mathrm{~mol}^{-1}$ and $T$ the ambient temperature in kelvin.

With measured time series of pressure $\left(P_{i}\right)$ and temperature $\left(T_{i}\right.$; Fig. 7), it is possible to relate the number of air moles in the tube $\left(n_{i}\right)$ to the atmospheric pressure at any given time during the flight:

$n_{i}=\frac{P_{i} V}{R T_{i}}$.

This number is maximum when the AirCore reaches the Earth's surface, i.e.,

$n^{\max }=\frac{P_{\mathrm{s}} V}{R T_{\mathrm{s}}}$,

where $P_{\mathrm{S}}$ and $T_{\mathrm{S}}$ correspond to the surface pressure and to the temperature of the AirCore when landing at the surface.

The critical orifice setting the flow during analysis at $38.5 \mathrm{sccm} \mathrm{min}{ }^{-1}$ and the controlled settings of the Picarro analysis cell ensure that the same number of moles are analyzed at every time step. In other words, during the sample analysis, the number of moles flown through the analyzer increases linearly with time. Hence, the number of moles at any time during the analysis is

$n_{i}=n^{\max } \frac{t_{i}}{\Delta t}$,

where $\Delta t$ is the total time duration of the analysis between the defined top and bottom of AirCore sample.

Using Eqs. (10) and (12), a specific pressure point can be associated with every Picarro measurement of the sample to retrieve the vertical profiles. Although the process is quite simple, the selections of start and end point of the sampled profile in the Picarro data as well as in the temperature and pressure data are delicate steps that have a direct impact on the resulting profiles (see Sect. 4.2). Two additional effects need to be taken into account: the pressure loss along the tube (P. Tans, personal communiction, 2014) and the accounting of potential losses of air samples during the recovery process (see Sect. 3.2).

\section{The StratoScience 2014 campaign}

\subsection{The EdS-Stratéole flight}

AirCore-HR was flown for the first time during the StratoScience campaign operated by the French space agency (CNES) in collaboration with the Canadian Space Agency (CSA) in Timmins (Ontario, Canada; $48.57 \mathrm{~N},-81.36 \mathrm{E}$ ) in August 2014. It participated in the third flight of the campaign: the EdS (effet de serre - greenhouse effect) Stratéole flight.

The carrier consists of a gondola that could accommodate a total of eight instruments including the AirCore-HR. All these instruments (consisting of small packages of several $\mathrm{kg}$ ) were brought together on the same structure with the aim of studying simultaneously several climate variables. In total, the gondola weighed $248 \mathrm{~kg}$.

In addition to AirCore-HR, two AirCores-GUF from Goethe University Frankfurt were also flown during this flight.

\subsection{Flight trajectory}

To fulfill the requirements of the eight instruments, the EdSStratéole flight had a very specific flight trajectory. The takeoff (release of the balloon) took place on 28 August 2014 at 20:33 local time in Timmins (00:33 UTC, 29 August 2014). After the ascent phase, the flight consisted of a monitored and controlled descent with two stops. Following a short stop at the ceiling at a barometric altitude of $14 \mathrm{hPa}(29 \mathrm{~km})$, an evacuation trap allowed us to let some gas out to engage in a descent phase down to a barometric altitude of $54 \mathrm{hPa}$ $(\approx 20 \mathrm{~km})$; the balloon then stabilized in a slow descent phase for $6 \mathrm{~h}$ down to the barometric altitude of $78 \mathrm{hPa}(\approx 18 \mathrm{~km})$. The separation between the flight chain and the balloon did not take place at the ceiling as for weather balloon flights but at the end of this slow descent at a barometric altitude of $78 \mathrm{hPa}$. The two elements (flight chain and balloon envelope) were then separated and engaged separately in faster descent, both finally landing in a dry area $350 \mathrm{~km}$ southeast of Timmins at 07:28 local time (11:28 UTC, 29 August 2014).

Figure 6 shows the flight profile together with the main operating states of AirCore-HR and AirCore-GUF. First, during a preparation phase on the ground before flight (marked in blue), the AirCore-HR was filled with the high-concentration calibration standard chosen as "fill gas". Then, the AirCore- 
(a) AirCore-HR

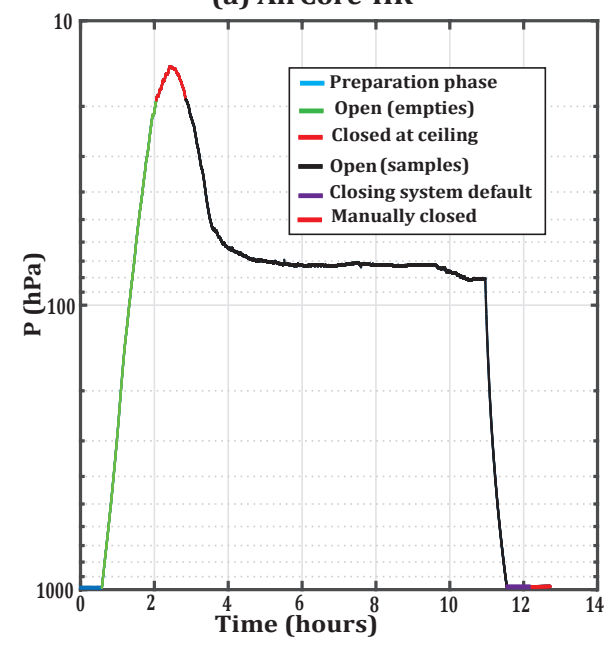

(b) AirCore-GUF

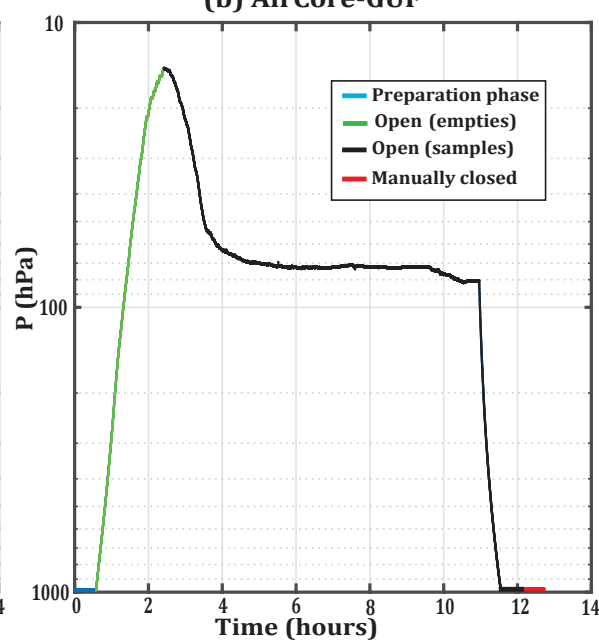

Figure 6. Flight plan from the StratoScience 2014 EdS-Stratéole flight on 29 August 2014 with main operating states of (a) AirCore-HR and (b) AirCore-GUF: the preparation phase, on the ground before flight (blue), ascent phase (green), descent phase (black) and closed (red).

HR was placed on the gondola and opened on one end just before takeoff. During the ascent phase (marked in green) the AirCore-HR emptied as it equilibrated with ambient pressure, thus evacuating fill gas. To preserve some part of the initial fill gas in the coil the AirCore-HR was closed at $19 \mathrm{hPa}$ ( $\approx 27 \mathrm{~km}$ ) through a signal sent to the solenoid valve. The AirCore-HR remained closed at ceiling (marked in red) and was then reopened by sending another signal to the solenoid valve at $19 \mathrm{hPa}$ during the descent phase. During all the descent phase (marked in black), the AirCore-HR remained open at one end. As the coil equilibrated with ambient pressure, air was pulled into the tube. At landing, after the pressure sensors on the electronic package detected no more pressure change, the solenoid valve closed in order to preserve the sample while waiting for recovery.

Joint efforts of CNES and CSA teams allowed access of the AirCores and analysis less than $3 \mathrm{~h}$ after landing. Unfortunately, at the end of the flight, the electronic circuit keeping the solenoid valve closed experienced a short power cut of about an hour, which resulted in sampled air evacuating from the AirCore. The AirCore-HR coil heated up after reaching the ground since it had been exposed to cold temperatures during the flight. During this period, the heating that occurred resulted in the loss of a fraction of the profile equivalent to the air sampled from 900 to $980 \mathrm{hPa}$. The loss of that fraction of the total sample had an impact on the retrieved vertical profiles (see Sect. 4.1).

The specific periods of interaction with ambient air of the AirCores-GUF are highlighted in Fig. 6b. The main difference between AirCore-HR and AirCore-GUF was the lack of a closing device for the latter. The light AirCores from Goethe University Frankfurt thus remained open until recovery. Being less insulated than AirCore-HR and exposed to the same cold temperatures during flight, AirCores-GUF lost

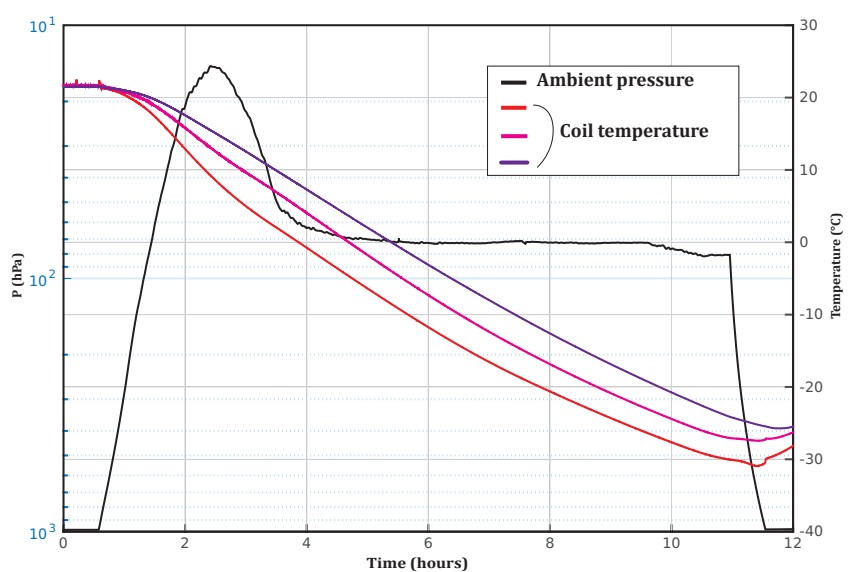

Figure 7. Recorded temperature from the three probes on the AirCore-HR and ambient pressure during the EdS-Stratéole flight on 29 August 2014. The three temperature probes (red, pink and purple lines) are presented in degrees Celsius as a function of time; the temperature axis is located on the right side. Ambient pressure (black line) is presented in $\mathrm{hPa}$ as a function of UTC time, with the vertical scale on the left side.

a fraction of the profile equivalent to the air sampled from about 780 to $980 \mathrm{hPa}$.

\subsection{Measurement of additional data}

In order to determine the vertical profiles of $\mathrm{CO}_{2}$ and $\mathrm{CH}_{4}$ from the analysis of sampled air, measurements of several atmospheric parameters are needed (see Sect. 2.3). The two most important parameters are the ambient pressure and the mean coil temperature. Those parameters are recorded by the AirCore-HR electronic data package (Sect. 2.2). Figure 7 shows the evolution of coil temperature and ambient pressure 

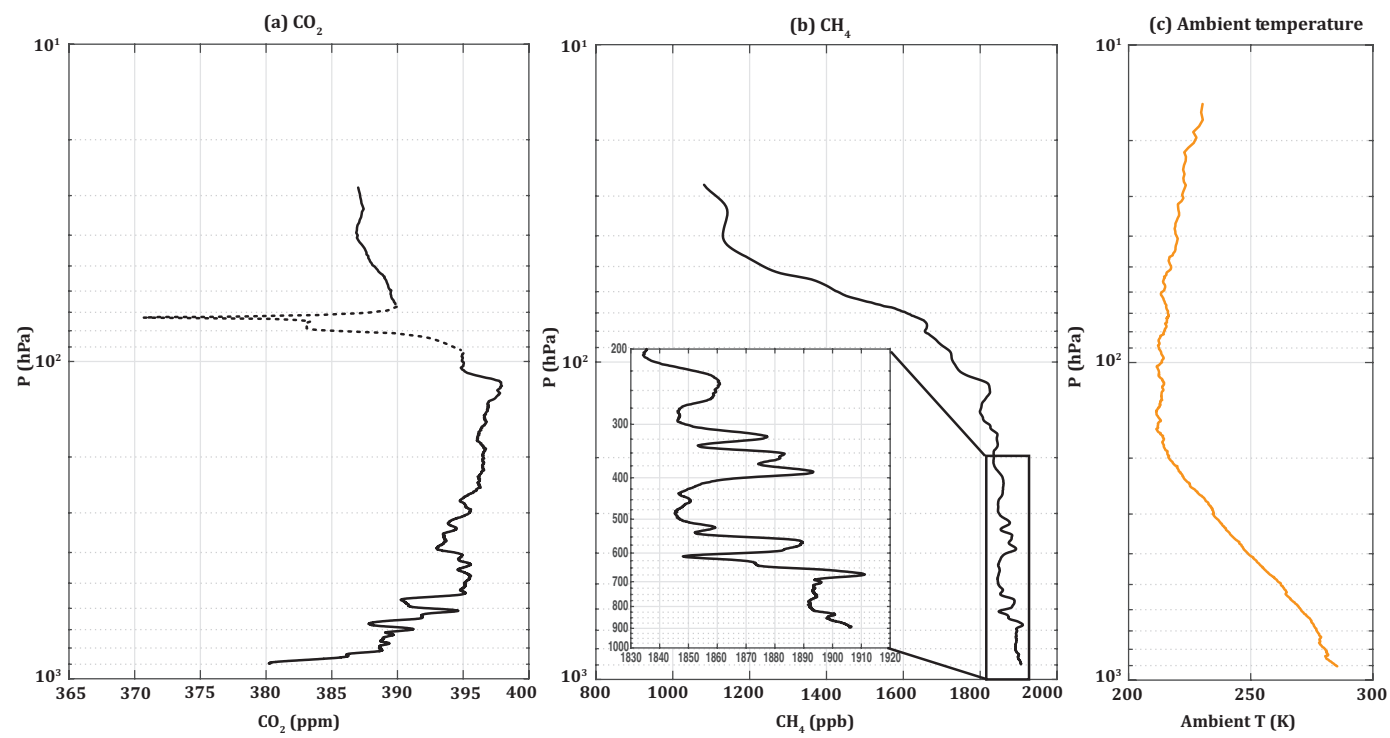

Figure 8. Vertical profiles retrieved from the air sampled with AirCore-HR on the EdS-Stratéole flight on 29 August 2014: (a) $\mathrm{CO}_{2}$ (ppm), (b) $\mathrm{CH}_{4}(\mathrm{ppb})$ and (c) ambient temperature $(\mathrm{K})$. The dotted line in the $\mathrm{CO}_{2}$ profile corresponds to a part of the profile with unrealistic $\mathrm{CO}_{2}$ values due to flight trajectory (see text).

measured during the flight. The temperatures recorded by the three temperature probes during flight are plotted in red (full, dashed, points) and reported on the right $y$ axis. Mean coil temperature is obtained by taking the mean of three temperatures recorded by independent probes located at different positions along the AirCore-HR. The ambient pressure during the flight is plotted in black and reported on the left $y$ axis.

Comparison between AirCore-HR and other pressure measurements highlighted a small drift in AirCore-HR data pressure recordings. Therefore the pressure profile recorded with the electronics of AirCore-HR has been corrected to fit the high precision of the records of a Paroscientific, Inc., absolute pressure gauge that is characterized by an accuracy of $10 \mathrm{~Pa}$ and a precision of $0.1 \mathrm{~Pa}$.

Additionally, GPS coordinates and altitudes from CNES were used to complete the dataset.

\section{Results: the 0-25 $\mathrm{km} \mathrm{CO} 2$ and $\mathrm{CH}_{4}$}

\subsection{The profiles}

Figure 8a and b show the $\mathrm{CO}_{2}$ and $\mathrm{CH}_{4}$ profiles measured during the StratoScience 2014 campaign. Each profile comprises about 1800 points on the vertical. As explained in Sect. 3.2, profiles stop at $900 \mathrm{hPa}$ due to the sample loss after landing. Both $\mathrm{CO}_{2}$ and $\mathrm{CH}_{4}$ AirCore-HR vertical profiles reveal thin structures of the atmosphere and air-mass transport signatures. Figure 8c shows the ambient temperature recorded onboard during flight. From this ambient temperature profile the tropopause was estimated to be at $162.1 \mathrm{hPa}$ according to the definition of the WMO thermal tropopause (Reichler et al., 2003).

In Fig. 8a, a strong decrease of $\mathrm{CO}_{2}$ can be observed in the first layers above ground. This is consistent with $\mathrm{CO}_{2}$ uptake by vegetation near the surface during the summer season. $\mathrm{CO}_{2}$ then reaches higher values in the free troposphere ( $\sim 393 \mathrm{ppm}$ ), with small variations (of $0.5-2 \mathrm{ppm}$ ) and two well-marked signatures at 700 and $600 \mathrm{hPa} . \mathrm{CO}_{2}$ reaches its highest value of $396 \mathrm{ppm}$ just above the tropopause. In the stratosphere, $\mathrm{CO}_{2}$ values are expected to be lower since the exchange rate between upper troposphere and lower stratosphere takes several years (Boering et al., 1981; Andrews et al., 2001; Engel et al., 2002). Above $\sim 110 \mathrm{hPa}, \mathrm{CO}_{2}$ mixing ratios decrease slowly from 396 to $385 \mathrm{ppm}$ at $30 \mathrm{hPa}$ with one structure captured at the very top of the profile between 30 and $40 \mathrm{hPa}$. This structure is correlated with a similar one at the same barometric altitude in the $\mathrm{CH}_{4}$ profile in Fig. 8b.

As can be seen in Fig. 8a, part of the $\mathrm{CO}_{2}$ profile between 70 and $90 \mathrm{hPa}$ is shown in dotted line. This corresponds to the range of the $7 \mathrm{~h}$ plateau phase (see Fig. 6) where unrealistically low $\mathrm{CO}_{2}$ values were sampled (visible in the $\mathrm{CO}_{2}$ data in Fig. 5 at the analysis times between 300 and 450 s). The origin of these very low values of $\mathrm{CO}_{2}$ is still debated. The alteration of $\mathrm{CO}_{2}$ sampled in this range was possibly caused by the dryer. Indeed, the magnesium perchlorate used as drying agent at the entry point of the tube is slightly reactive with $\mathrm{CO}_{2}$ and inert with $\mathrm{CH}_{4}$. Because of the long exposure $(\sim 7 \mathrm{~h})$ to this drying agent during the plateau phase, enhanced by air coming in and out of the tube because of oscillations of the gondola around $80 \mathrm{hPa}$, the magnesium per- 
(a) $\mathrm{CO}_{2}$

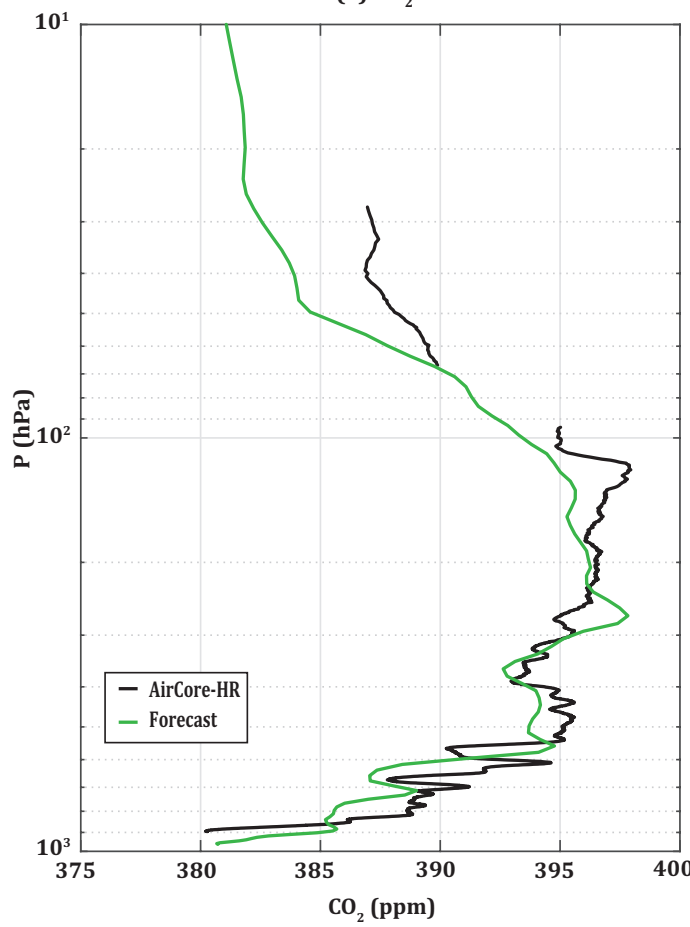

(b) $\mathrm{CH}_{4}$

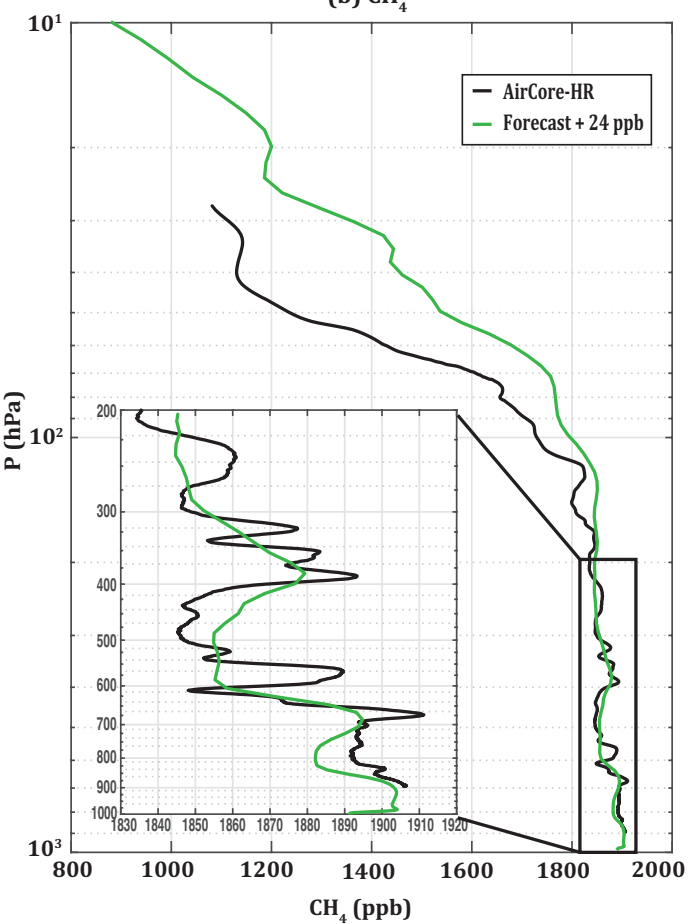

Figure 9. Comparison of AirCore-HR (a) $\mathrm{CO}_{2}$ and (b) $\mathrm{CH}_{4}$ vertical profiles (black) with co-located high-resolution forecast (green) from CAMS-ECMWF at landing coordinates on 29 August 2014 at 12:00 UTC; 24 ppb were added to the $\mathrm{CH}_{4}$ high-resolution forecast.

chlorate might have impacted $\mathrm{CO}_{2}$ sampled by the AirCore$\mathrm{HR}$. Because the dryer is inert to $\mathrm{CH}_{4}$, no impact is seen on $\mathrm{CH}_{4}$ profile. Other explanations might be that the air sampled during this particular phase was polluted through interaction with polystyrene, with the balloon envelope (pumping up some of the ambient air as they re-equilibrate with ambient air during this long phase) or by chemical interaction with helium from the balloon (during some short reascent phases).

The $\mathrm{CH}_{4}$ vertical profile is presented in Fig. 8b. Mixing ratios of $\mathrm{CH}_{4}$ have a small variability in the troposphere between 1800 and $1880 \mathrm{ppb}$. The zoom on the tropospheric part (between 200 and $1000 \mathrm{hPa}$ ) reveals pronounced structures captured in the troposphere, particularly in the region from 200 to $700 \mathrm{hPa}$. These could be caused by transport or variability in the emissions. The strong decrease of $\mathrm{CH}_{4}$ in the stratosphere is particularly easy to see in Fig. 8b, with values of $\sim 1800 \mathrm{ppb}$ near the tropopause at $120 \mathrm{hPa}$ to $1100 \mathrm{ppb}$ at $30 \mathrm{hPa}$. Along the slopes, several structures can be identified around $80 \mathrm{hPa}$ and between 30 and $40 \mathrm{hPa}$, revealing transport patterns in the stratosphere.

A comparison between Fig. 8a and b shows $\mathrm{CO}_{2}$ variability is higher near the ground, whereas $\mathrm{CH}_{4}$ variability is higher in the mid-to-upper troposphere and in the stratosphere. This is in agreement with the fact that $\mathrm{CO}_{2}$ may have negative and positive anomalies at the surface (associated mainly with vegetation uptake and anthropogenic emissions), whereas $\mathrm{CH}_{4}$ has mostly positive anomalies coming from the surface and negative anomalies coming from the stratosphere.

A comparison was performed with $\mathrm{CO}_{2}$ and $\mathrm{CH}_{4}$ forecasts from the Copernicus Atmosphere Monitoring Service (CAMS) using the European Centre for Medium-range Weather Forecasts (ECMWF) model (Agustí-Panareda et al., 2014; Massart et al., 2014). This comparison is presented in Fig. 9. The tracer transport in the forecast is constrained with meteorological observations by re-initializing the forecast every $24 \mathrm{~h}$ with operational ECMWF analyses, whereas the atmospheric $\mathrm{CO}_{2}$ and $\mathrm{CH}_{4}$ tracers are cycled from one 1-day forecast to the next, as in a free run. Therefore, the forecast is essentially a model simulation with state-of-the-art representation of tracer transport available in forecast mode (http://macc.copernicus-atmosphere.eu/d/ services/gac/nrt/rt_fields_ghg). The CAMS-ECMWF $\mathrm{CO}_{2}$ and $\mathrm{CH}_{4}$ forecasts used here have a horizontal resolution of around $16 \mathrm{~km} \times 16 \mathrm{~km}$ and a vertical resolution of $137 \mathrm{lev}$ els from the surface to $0.01 \mathrm{hPa}$. These forecasts have been collocated in space and time with AirCore-HR landing coordinates. $24 \mathrm{ppb}$ were added to the CAMS-ECMWF $\mathrm{CH}_{4}$ high-resolution forecast to emphasize the good agreement on structures rather than focusing on the bias, which may be attributed to incorrect surface fluxes or issues with air-mass exchanges along the vertical.

The agreement between both $\mathrm{CO}_{2}$ profiles (Fig. 9a) is satisfying throughout the troposphere in terms of structures. 
The forecast correctly reproduces the strong decrease in $\mathrm{CO}_{2}$ from $800 \mathrm{hPa}$ to the surface, as well as the increase in concentration from 800 to $600 \mathrm{hPa}$ and a lower increase from $600 \mathrm{hPa}$. In the upper troposphere, from $300 \mathrm{hPa}$ up to the tropopause at $150 \mathrm{hPa}$, the forecast displays different structures than those measured by the AirCore-HR. In the lower stratosphere (from 150 to $90 \mathrm{hPa}$ ), the AirCore-HR and the CAMS-ECMWF forecasts both reveal a decrease in $\mathrm{CO}_{2}$ starting from just above the tropopause up to the top of the stratosphere.

Although fewer vertical structures are seen in the forecast, the $\mathrm{CH}_{4}$ mixing ratios and position of the broader vertical structures fit quite well with the measurements up to $200 \mathrm{hPa}$ (Fig. 9b). For lower pressures, the decrease of $\mathrm{CH}_{4}$ measured by AirCore-HR is much more pronounced than the one simulated by the forecast. This is a known problem in the CAMS-ECMWF model, which is currently being investigated (A. Agusti-Panareda, S. Massart, personal communication, 2016) and was also discussed in Verma et al. (2016).

\subsection{Associated uncertainties}

Monte Carlo simulations were performed to assess the uncertainty associated with the retrieved constituent profiles. The retrieval process of the vertical profiles was iterated a 1000 times by randomly changing the original datasets within the estimated uncertainty range of every identified uncertainty source. This allowed us to produce a set of 1000 slightly different outcomes for the vertical profiles in terms of both mixing ratios and vertical position. A standard deviation of the mixing ratios at a given position was then calculated based on this dataset. In these simulations we took into account the following uncertainties:

i. The accuracy of the gas analyzer: Picarro measurement accuracy was defined as a Gaussian standard deviation of the mixing ratios based on the instrument specification (i.e., deviations of $0.5 \mathrm{ppb}$ for $\mathrm{CH}_{4}$ and $0.07 \mathrm{ppm}$ for $\mathrm{CO}_{2}$; Crosson, 2008).

ii. The mean temperature profile: to account for the impact of temperature correction, the temperature profile was randomly chosen among the three profiles measured by the three probes. Indeed, the three temperature probes are placed at different positions along the tube (near the entrance, in the middle of the AirCore and near the closed end) and, depending on the distance to the inlet, they have recorded different temperatures along the AirCore. Choosing randomly between one of the three probes is thus the conservative way to account for the uncertainty related to the mean temperature of the AirCore.

iii. The pressure profile: an uncertainty of $0.1 \mathrm{~Pa}$ corresponding to the accuracy of the Paroscientific, Inc., absolute pressure gauge was used.
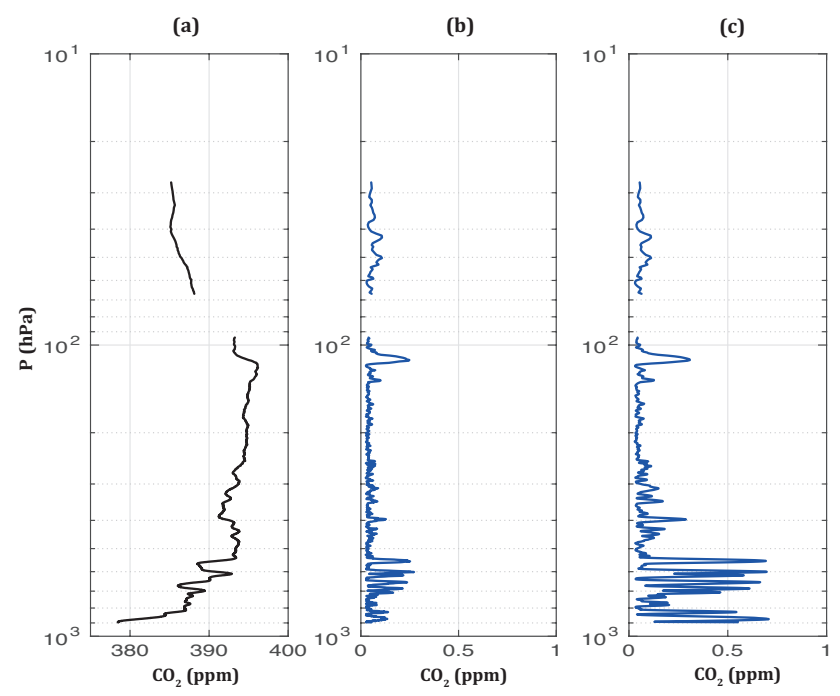

Figure 10. (a) AirCore-HR $\mathrm{CO}_{2}$ vertical profile, (b) $\mathrm{CO}_{2}$ uncertainty without taking the potential loss of air into account (see Sect. 4.2, point v) and (c) overall $\mathrm{CO}_{2}$ uncertainty.

iv. The selection of the sample: the choice of the exact midpoint of transition between either push gas and sample or remaining gas and sample (see Sect. 2.3) has an impact on the altitude of both ends of the profile. A random uncertainty of \pm 1 Picarro measurement point was defined for both uncertainties.

v. The potential loss of air sample resulting from the tube remaining open after landing as occurred during this flight (see Sect. 3.2): an uncertainty of $\pm 10 \mathrm{hPa}$ was associated with the bottom pressure correction that was defined to take the air loss into account.

The uncertainties discussed here are related to the analysis and processing of the sampled air and are only valid for the AirCore-HR in the case of this flight and may have different results in other situations. The $\mathrm{CO}_{2}$ uncertainties do not take into account the potential interactions with the drying agent that are hard to quantify and need to be further studied (see Sect. 4.3). The uncertainties associated with the AirCore-HR $\mathrm{CO}_{2}$ and $\mathrm{CH}_{4}$ profiles were calculated for the five uncertainty sources together but also separately to estimate the influence of each individual source of uncertainty. The overall resulting uncertainties associated with the mixing ratios of $\mathrm{CO}_{2}$ are presented in Fig. 10 and those associated with the $\mathrm{CH}_{4}$ mixing ratios are presented in Fig. 11. Figures 10a and 11a show a reminder of the vertical profiles of $\mathrm{CO}_{2}$ or $\mathrm{CH}_{4}$, respectively. Figures $10 \mathrm{~b}$ and $11 \mathrm{~b}$ show the uncertainties without taking the uncertainty source (v) into account in order to illustrate what the expected uncertainties would be in an ideal case where the closing system would have worked. Figures $10 \mathrm{c}$ and $11 \mathrm{c}$ show the overall uncertainties associated with the vertical profiles accounting for all uncertainties sources previously listed. 
(a)

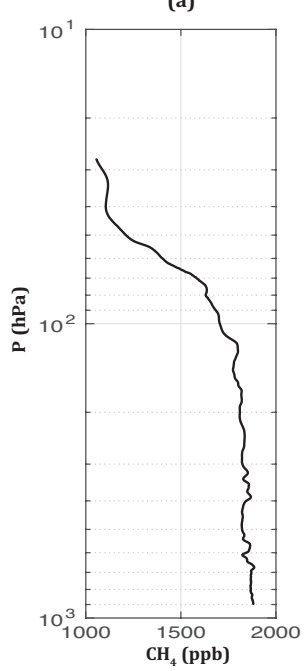

(b)

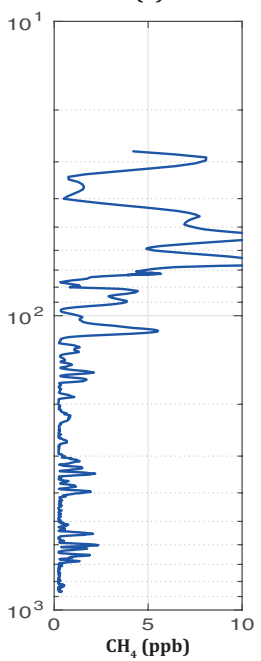

(c)

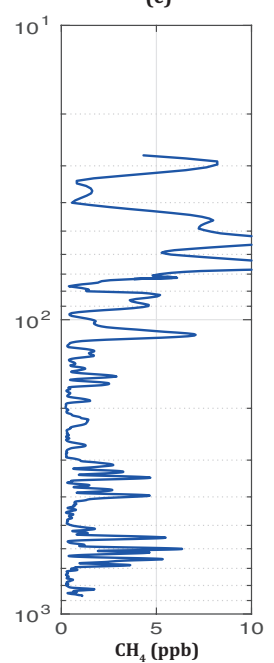

Figure 11. (a) AirCore-HR $\mathrm{CH}_{4}$ vertical profile, (b) $\mathrm{CH}_{4}$ uncertainty without taking the potential loss of air into account (see Sect. 4.2, point v) and (c) overall $\mathrm{CH}_{4}$ uncertainty.

Comparing Fig. 10b with Fig. 10c and Fig. 11b with Fig. $11 \mathrm{c}$ shows that, for both $\mathrm{CO}_{2}$ and $\mathrm{CH}_{4}$, the uncertainty related to the bottom pressure correction has an important impact on the uncertainties estimated in the troposphere, although in the stratosphere the uncertainties remain relatively unaffected by this. Indeed the fraction of the overall uncertainties (Figs. 10c and 11c) that is related to the loss of air is above $80 \%$ in the troposphere and drops to about $30 \%$ in the stratosphere. The dominating uncertainty source in the stratosphere is related to the selection of the sample. Misselecting the transition point between the gas in the AirCore sample and the calibrated standard by only one measurement has an important impact on the positioning of the stratospheric part of the profiles. Indeed, the whole stratospheric air sampled by the AirCore accounts for about $8 \%$ of the total sample $(\sim 150$ points out of $\sim 1800$ total points $)$ but corresponds to $\approx 15 \mathrm{~km}$ of the $25 \mathrm{~km}$ profile. Hence, a difference of a single measurement point in the positioning of the profile does matter.

Additionally, the impact of the variability in the measurements of the three temperature probes has been studied. It was found that temperature uncertainty has a very limited influence on the overall uncertainties, of the order of $6 \%$, despite differences of several degrees Celsius (Fig. 7). Although differences up to several degrees Celsius are observed between the measurement, the overall variation of the temperature is captured similarly by the three temperature probes (Fig. 7). The increase of sampled moles in the AirCore at each pressure level as well as the total number of sampled moles in the AirCore are almost unchanged when considering one or the other temperature sensor. This comes from the fact that, during the fast descent phase in the troposphere

when most of the sampled air is captured, the temperature remains very stable.

Overall, the average uncertainty on the $\mathrm{CO}_{2}$ profile (Fig. 10c) is $0.24 \mathrm{ppm}$ throughout the column. The average uncertainty in the troposphere is $0.25 \mathrm{ppm}$ with relatively higher uncertainties in the bottom of the profile where important variations of $\mathrm{CO}_{2}$ are measured, indicating that the slightest positioning uncertainty translates into mixing ratio uncertainties. For the whole stratosphere above $120 \mathrm{hPa}$, where the $\mathrm{CO}_{2}$ profile is more stable, the average uncertainty drops to $0.11 \mathrm{ppm}$.

The average uncertainty on the overall $\mathrm{CH}_{4}$ profile (Fig. 11c) is $2.78 \mathrm{ppb}$. In the stratosphere, above the tropopause at $120 \mathrm{hPa}, \mathrm{CH}_{4}$ uncertainties are quite variable along the profile and can be as high as $10 \mathrm{ppb}$ locally but on average are estimated to be $6.42 \mathrm{ppb}$. Such high values stem directly from high vertical gradients in mixing ratios: in that case, the assumed error on the vertical positioning of the profiles translates into higher uncertainties. In the troposphere, the average uncertainty for the $\mathrm{CH}_{4}$ profile is below $2 \mathrm{ppb}$ with sometimes values up to $5 \mathrm{ppb}$ where the vertical profile shows transport structures of $30 \mathrm{ppb}$ or more along the vertical in the troposphere.

\subsection{Comparison between AirCores with different resolutions}

\subsubsection{Overall comparison}

Benefiting from the accommodation of several AirCores on board the CNES gondola, the AirCore-HR profiles can be compared with those of the lighter AirCores-GUF (see Sect. 3). AirCore-GUF air samples were processed at LMD using the same methodology as for AirCore-HR (Sect. 2.3). The processing took into account the fact that AirCores-GUF remained open for $3 \mathrm{~h}$ before being manually closed at recovery leading to the loss of the bottom of the profile between 980 and $780 \mathrm{hPa}$ (see Sect. 3.2). Both AirCore-GUF being identical, the comparison is presented with only one AirCore-GUF in order to focus on the comparison between AirCores with different resolutions. Figure 12a and b show the comparison of AirCore-HR and one AirCore-GUF $\mathrm{CO}_{2}$ and $\mathrm{CH}_{4}$ profiles.

The particular descent profile of this flight had several impacts on the AirCore-GUF profiles:

i. As for AirCore-HR, unrealistic low values of $\mathrm{CO}_{2}$ were sampled during the long plateau phase that happened between 70 and $90 \mathrm{hPa}$.

ii. Since the lower-resolution AirCore-GUF captured a smaller volume than AirCore-HR, the stratospheric part of the profile was impacted by diffusion during the $7 \mathrm{~h}$ plateau phase. Indeed, during the plateau phase at about $90 \mathrm{hPa}$, the air sampled from 20 to $90 \mathrm{hPa}$ by AirCoreGUF remained in the first tube of $20 \mathrm{~m} / 8 \mathrm{~mm}$ diameter 

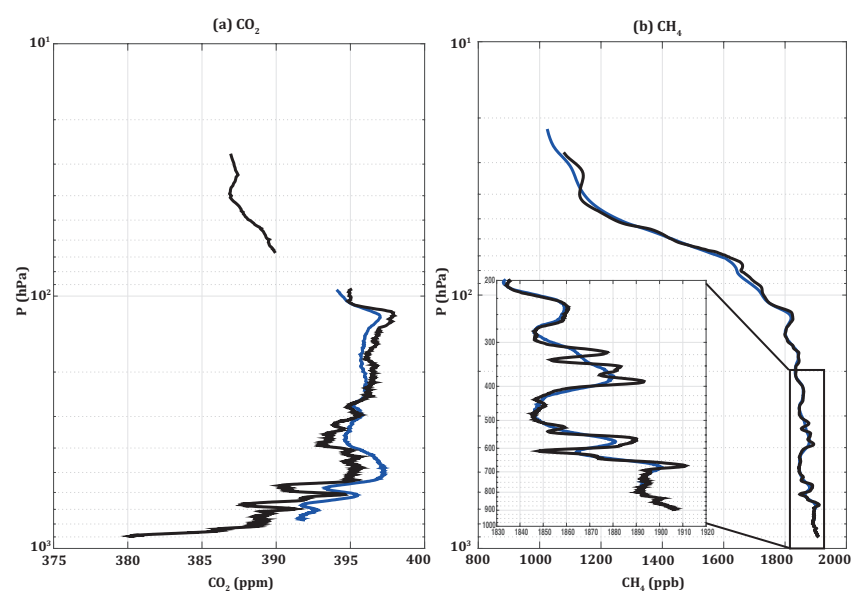

Figure 12. Vertical profiles retrieved from the air sampled with the AirCore-HR and an AirCore-GUF on the EdS-Stratéole flight on 29 August 2014. (a) $\mathrm{CO}_{2}$ (ppm); (b) $\mathrm{CH}_{4}$ (ppb). The dotted line in the $\mathrm{CO}_{2}$ profiles corresponds to unrealistic $\mathrm{CO}_{2}$ values sampled during the long plateau phase (see Sect. 3.2).

whereas it was stored over the $100 \mathrm{~m} / 0.25 \mathrm{in} .(6.35 \mathrm{~mm})$ tube for AirCore-HR. This led to a more intense diffusion in the AirCore-GUF sample.

Therefore, all the $\mathrm{CO}_{2}$ sampled above $100 \mathrm{hPa}$ with AirCore-GUF was probably altered by the combination of unrealistic low values of $\mathrm{CO}_{2}$ acquired during the plateau phase and the diffusion effects. This part of the profile that should not be considered is shown in dotted line as with AirCore-HR $\mathrm{CO}_{2}$. Only AirCore-GUF $\mathrm{CO}_{2}$ sampled in the troposphere below $100 \mathrm{hPa}$ should be compared, where residual effects from this phase are minimal. Concerning $\mathrm{CH}_{4}$, which was not impacted by the dryer during the plateau phase, only the difficulty of properly modeling the diffusion inside the tube remains. The full AirCore-GUF $\mathrm{CH}_{4}$ profile is shown but the stratospheric part of the profile should thus be taken with caution.

The comparison between AirCore-HR (black) and AirCore-GUF (blue) highlights that both $\mathrm{CO}_{2}$ profiles (Fig. 12a) have a good agreement in terms of structures. In particular, the impact of vertical resolution is seen in Fig. 12a, with less structures captured by the lowerresolution AirCore. However, there is a variable but noticeable bias between the profiles (up to $3 \mathrm{ppm}$ in some part of the profiles).

For $\mathrm{CH}_{4}$, Fig. $12 \mathrm{~b}$ reveals that the agreement is excellent between AirCore-HR and AirCore-GUF. The zoom on the tropospheric part (between 200 and $1000 \mathrm{hPa}$ ) shows that the different AirCores capture the same structures and allow us to retrieve similar vertical profiles in terms of both structures and mixing ratios albeit at a different resolution. In the stratosphere, both AirCores capture the position and inclination of the decreasing slope of methane. However, some stronger differences can be seen in terms of mixing ratios between both profiles between 70 and $90 \mathrm{hPa}$ or between 30 and $40 \mathrm{hPa}$. In these ranges, similar structures are captured by both AirCores but seem to be very strongly impacted by diffusion in the AirCore-GUF $\mathrm{CH}_{4}$ profile. This illustrates the impact of diffusion, which is stronger for AirCore-GUF than for AirCore-HR during the long plateau phase.

Overall, the comparison between both AirCores reveals that the high resolution captures more information on the vertical distribution along the atmospheric column.

\subsubsection{Degradation of the resolution}

To perform a fair comparison between the different AirCore profiles, the degradation of the resolution of AirCore-HR profiles to that of lower-resolution AirCore-GUF has to be performed. This exercise aims also to evaluate the theoretical calculation of the expected resolution (Sect. 2.1).

The vertical resolutions shown in Fig. 2 were calculated for a standard atmosphere and air sampled from $10 \mathrm{hPa}$ to a ground pressure of $1013.25 \mathrm{hPa}$. In order to account for the sampling that occurred during flight and how the sampled air was distributed within the tubes, the vertical resolution of AirCores-GUF was recalculated with the specific parameters of the flight for both $\mathrm{CO}_{2}$ and $\mathrm{CH}_{4}$.

Degradation of the AirCore-HR profiles is performed through the convolution with a Gaussian window with a standard deviation of the lower vertical resolution at each given altitude:

$g(x)=\frac{1}{\sigma \sqrt{2 \pi}} \exp \left(-\frac{x^{2}}{2 \sigma^{2}}\right)$,

where $\sigma$ is the standard deviation (i.e., the vertical resolution) at a given vertical position $x$.

It allows retrieving a degraded version of the profiles:

degraded $\mathrm{X}_{\mathrm{CH}_{4}}\left(x_{0}\right)=\int \mathrm{CH}_{4}(x) g\left(x-x_{0}\right) \mathrm{d} x$.

The degraded version of the $\mathrm{CO}_{2}$ profile is calculated similarly. To avoid the parts of the profiles that may have been affected by the strong diffusion during the long plateau phase in the flight profile, the comparison with degraded AirCore-HR profiles is only presented for pressures higher than $200 \mathrm{hPa}$.

The effect of the degradation of the AirCore-HR profile to the lower resolution of AirCore-GUF is presented in Figs. 13a and 14a. The differences between AirCore-GUF and the smoothed version of AirCore-HR (degraded to the vertical resolution of AirCore-GUF) are shown in Figs. 13b and $14 \mathrm{~b}$.

The comparison of the $\mathrm{CO}_{2}$ profiles in Fig. 13a shows that when the lower vertical resolution of AirCore-GUF is taken into account, both AirCores display very similar structures. However, a bias remains between both profiles. The difference between AirCore-GUF and the smoothed AirCoreHR (Fig. 13b) highlights that this bias varies linearly from 
(a)

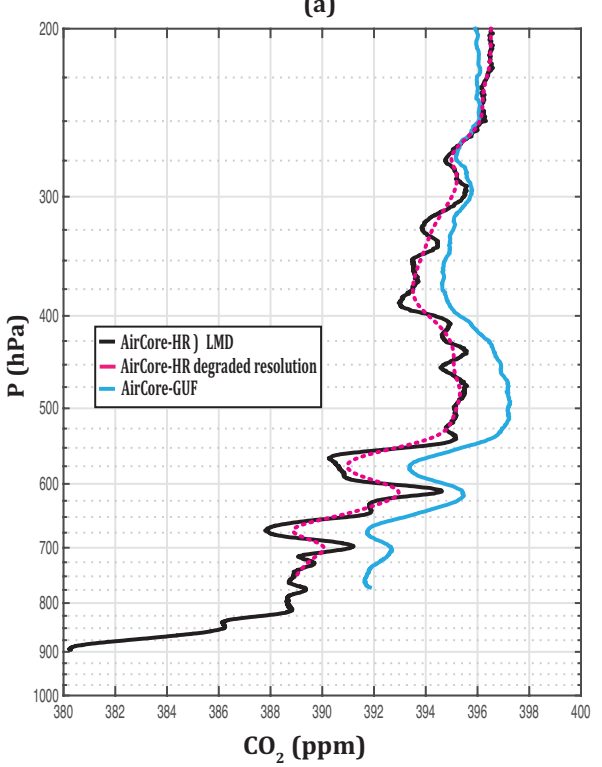

(b)

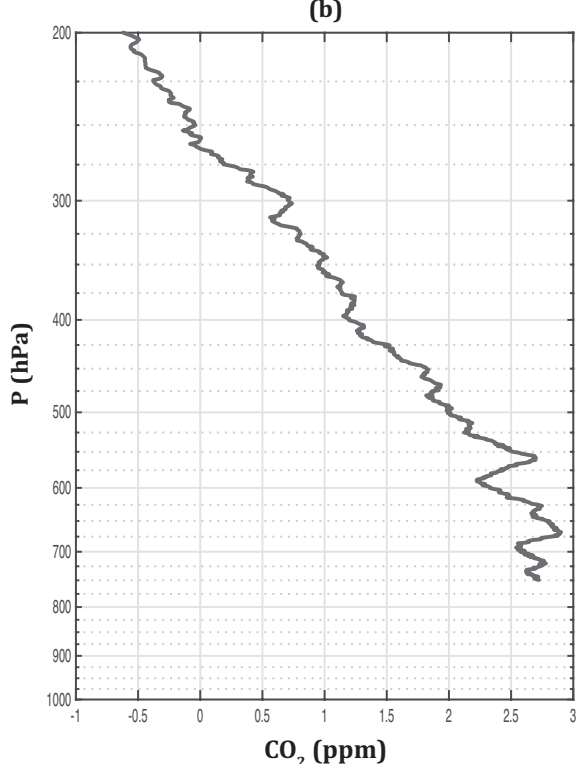

Figure 13. (a) $\mathrm{CO}_{2}$ vertical profiles from AirCore-HR in full resolution (black), from AirCore-HR in "degraded resolution" (pink) and from AirCore-GUF (blue). (b) Residual of the difference AirCore-GUF-AirCore-HR in "degraded resolution".

(a)

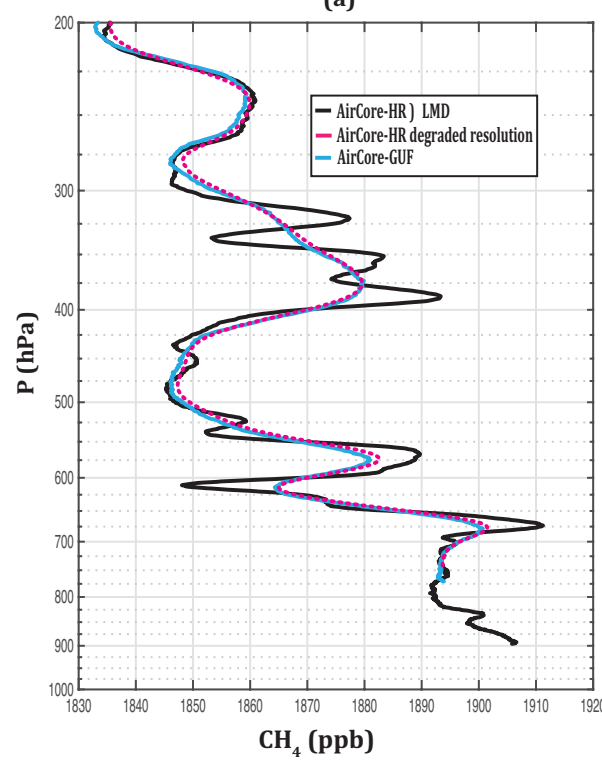

(b)

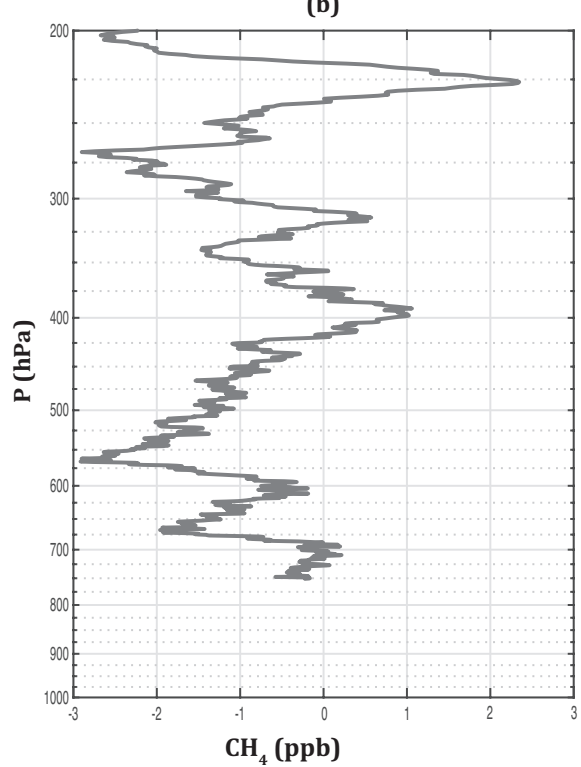

Figure 14. (a) $\mathrm{CH}_{4}$ vertical profiles from AirCore-HR in full resolution (black), from AirCore-HR in "degraded resolution" (pink) and from AirCore-GUF (blue). (b) Residual of the difference AirCore-GUF-AirCore-HR in "degraded resolution".

$-1 \mathrm{ppm}$ at $200 \mathrm{hPa}$ up to $3 \mathrm{ppm}$ at $780 \mathrm{hPa}$. The reasons of these observed differences are still debated. The main hypotheses are that it could be related to some kind of "memory effect" of the tubing to the previously stored calibrated gas or the individual dryers from different AirCores may affect the $\mathrm{CO}_{2}$ samples slightly differently when capturing $\mathrm{CO}_{2}$. Overall, the problem highlights that there are some remain- ing questions regarding $\mathrm{CO}_{2}$ sampling and that some potential interferences with $\mathrm{CO}_{2}$ have to be studied more closely.

Concerning $\mathrm{CH}_{4}$, the degraded AirCore-HR profile (pink) smears out the smaller structures that were captured by the high resolution and matches perfectly the AirCoreGUF profile both in terms of structures and mixing ratios. The difference between AirCore-GUF (blue) and the smoothed AirCore-HR profile (pink) varies between -2.7 
and $+2.1 \mathrm{ppb}$ (Fig. 14b), which is in agreement with the $2.8 \mathrm{ppb}$ average uncertainty that can be associated with the AirCore-HR profile (see Sect. 4.2). In addition to allowing the comparison of AirCore-HR profiles with those of lowerresolution AirCores, the excellent agreement of both $\mathrm{CH}_{4}$ profiles validates the computation of theoretical vertical resolution presented in Sect. 2.1.2.

\section{Conclusions}

In this paper, a new AirCore (AirCore-HR) allowing highresolution measurements of $\mathrm{CO}_{2}$ and $\mathrm{CH}_{4}$ from the ground up to almost $30 \mathrm{~km}$ is presented. Thanks to the combination of two tubes, it allows retaining air samples with a vertical resolution better than $500 \mathrm{~m}$ up to $20 \mathrm{~km}$ when the analysis is performed within $6 \mathrm{~h}$ after landing of the instruments. As for any AirCore, the final resolution depends on the delay between landing and analysis.

The AirCore-HR was flown for the first time on a multiinstrument gondola, which allowed us to perform comparisons of the vertical profiles retrieved with AirCore-HR and lower-resolution AirCore-GUF. The degradation of the profile given by AirCore-HR to the resolution of AirCore-GUF revealed an excellent agreement between both profiles for $\mathrm{CH}_{4}$, which fully validates the theory behind AirCores.

$\mathrm{CO}_{2}$ profiles retrieved from the AirCores on this flight have revealed unexpected structures between 60 and $90 \mathrm{hPa}$ when the flight experienced a long plateau phase of about $7 \mathrm{~h}$ during descent, not seen on $\mathrm{CH}_{4}$. It is suspected that the magnesium perchlorate used as drying agent at the inlet of the AirCores inert to $\mathrm{CH}_{4}$ may have played a role in the alteration of $\mathrm{CO}_{2}$ during this particular phase at low pressure. Moreover, the comparison of $\mathrm{CO}_{2}$ profiles has highlighted that the agreement is good in terms of structures but an important and variable bias is seen between profiles. This bias is also suspected to come from potential interaction with the dryer and shows that $\mathrm{CO}_{2}$ sampling aspects with AirCores as well as these potential impacts of the drying agent have to be further studied. Therefore, specific tests are planned during the future StratoScience 2017 campaign that will take place in March-April 2017 in Alice Springs, Australia. These tests will include comparing several independent AirCores flown on the same gondola with and without a dryer at inlet.

By designing a method that takes into account all the sources of uncertainties in the processing of the data, the overall uncertainty is estimated to be less than $3 \mathrm{ppb}$ on the $\mathrm{CH}_{4}$ profile and less then $0.3 \mathrm{ppm}$ on the $\mathrm{CO}_{2}$ profile. A particular issue during the flight with the closing system has led to the loss of part of the sampled air. Therefore the highest pressure point sampled by the AirCore-HR had to be corrected. An uncertainty of $10 \mathrm{hPa}$ was associated with this correction and it was estimated that this uncertainty is responsible for $\sim 80 \%$ of the overall uncertainty on the profiles. In an ideal case where the system would close and retain the com- plete sample, it would be possible to know more precisely the pressure at which air was sampled last and thus to improve the overall uncertainty to about $0.1 \mathrm{ppm}$ for $\mathrm{CO}_{2}$ and $2 \mathrm{ppb}$ for $\mathrm{CH}_{4}$.

Comparison between AirCore data and forecasts from CAMS-ECMWF has yielded satisfying agreements between AirCore-HR profiles and simulated profiles. In particular, well-pronounced vertical transport signatures in the troposphere in both $\mathrm{CO}_{2}$ and $\mathrm{CH}_{4}$ profiles are similar for both the forecasts and AirCore-HR profiles. In the stratosphere, the AirCore-HR $\mathrm{CH}_{4}$ profile seems to indicate that the decrease of stratospheric $\mathrm{CH}_{4}$ in the forecasts is too slow, which may have an important impact when deriving total or partial columns of $\mathrm{CH}_{4}$ from the analyses.

This comparison illustrates the potential of AirCores to evaluate atmospheric transport models, as well as GHG satellite retrievals from TIR and SWIR instruments. In particular, light AirCores flown from weather balloons could be deployed at various locations to complete an effective system together with ground stations and regular aircraft campaigns. Such lightweight systems could also contribute to specific campaigns for calibration and validation of future space missions. In order to fit these applications, the spatial and temporal resolution requirements necessary to evaluate the models or satellite retrievals efficiently need to be assessed.

Along with the development of robust lightweight systems, it is also important to continue development strategies of AirCores for large platforms carrying heavy payloads. Such platforms, flown during specific stratospheric balloon campaigns, allow unique multi-instrument measurements of the same or complementary atmospheric variables. The simultaneous use of laser-diode spectrometers, cryosamplers and AirCores, which can only be performed during these specific campaigns, is necessary to evaluate the retrievals performed with various AirCores and test improvements of the instruments.

Data availability. AirCore data presented in this paper are available via the Ether database through the following link: http:// cds-espri.ipsl.upmc.fr/etherTypo/index.php?id=1792\&L=1.

Competing interests. The authors declare that they have no conflict of interest.

Acknowledgements. This work was supported by CNES and benefited during the StratoScience 2014 campaign from the infrastructure developed by CSA in Timmins. École Polytechnique provided additional funding for the instruments and funded the 6-month sabbatical of Colm Sweeney from NOAA to LMD. The first author is funded by EIT/Climate-KIC under contract with UPMC. Technical support to develop the instrument was provided by Olivier Bousquet and Olivier Godde from the technical team of LMD. Sebastien Massart and Anna Agusti-Panareda from 
ECMWF provided collocated CAMS-ECMWF data generated using Copernicus Atmosphere Monitoring Service Information (2016) and are to be thanked for their valuable input and scientific discussions. The development and deployment of AirCore at GUF was funded by the German Federal Ministry of Education and Research (BMBF) within the ROMIC program under project 01LG1221A.

Edited by: M. Hamilton

Reviewed by: two anonymous referees

\section{References}

Agustí-Panareda, A., Massart, S., Chevallier, F., Boussetta, S., Balsamo, G., Beljaars, A., Ciais, P., Deutscher, N. M., Engelen, R., Jones, L., Kivi, R., Paris, J.-D., Peuch, V.-H., Sherlock, V., Vermeulen, A. T., Wennberg, P. O., and Wunch, D.: Forecasting global atmospheric $\mathrm{CO}_{2}$, Atmos. Chem. Phys., 14, 1195911983, https://doi.org/10.5194/acp-14-11959-2014, 2014.

Andrews, A. E., Boering, K. A., Daube, B. C., Wofsy, S. c., Loewenstein, M., Jost, H., Podolske, J. R., Webster, C. R., Herman, R. L., Scott, D. C., Flesch, G. J., Moyer, E. J., Elkins, J. W., Dutton, G. S., Hurst, D. F., Moore, F. L., Ray, E. A., Romashkin, P. A., and Strahan, S. E.: Mean ages of stratospheric air derived from in situ observations of $\mathrm{CO}_{2}, \mathrm{CH}_{4}$, and $\mathrm{N}_{2} \mathrm{O}$, J. Geophys. Res.Biogeo., 106, 32295-32314, 2001

Boering, K., Wofsy, S., Daube, B., Schneider, H., Loewenstein, M., Poldolske, J., and Conway, T.: Stratospheric mean ages and transport rates from obM servations of carbon dioxide and nitrous oxide, Science, 274, 1340-1343, 1981.

Butz, A., Guerlet, S., Hasekamp, O., Schepers, D., Galli, A., Aben, I., Frankenberg, C., Hartmann, J.-M., Tran, H., Kuze, A., Keppel-Aleks, G., Toon, G., Wunch, D., Wennberg, P., Deutscher, N., Griffith, D., Macatangay, R., Messerschmidt, J., Notholt, J., and Warneke, T.: Toward accurate $\mathrm{CO}_{2}$ and $\mathrm{CH}_{4}$ observations from GOSAT, Geophys. Res. Lett., 38, L14812, https://doi.org/10.1029/2011GL047888, 2011.

Chedin, A., Scott, N. A., Wahiche, C., and Moulinier, P.: The Improved Initialization Inversion Method: A High Resolution Physical Method for Temperature Retrievals from Satellites of the TIROS-N Series, J. Clim. Appl. Meteorol., 24, 128-143, https://doi.org/10.1175/15200450(1985)024<0128:TIIIMA>2.0.CO;2, 1985.

Chen, H., Winderlich, J., Gerbig, C., Hoefer, A., Rella, C. W., Crosson, E. R., Van Pelt, A. D., Steinbach, J., Kolle, O., Beck, V., Daube, B. C., Gottlieb, E. W., Chow, V. Y., Santoni, G. W., and Wofsy, S. C.: High-accuracy continuous airborne measurements of greenhouse gases $\left(\mathrm{CO}_{2}\right.$ and $\left.\mathrm{CH}_{4}\right)$ using the cavity ringdown spectroscopy (CRDS) technique, Atmos. Meas. Tech., 3, 375-386, https://doi.org/10.5194/amt-3-375-2010, 2010.

Crevoisier, C., Chedin, A., and Scott, N. A.: AIRS channel selection for $\mathrm{CO}_{2}$ and other trace-gas retrievals, Q. J. Roy. Meteorol. Soc., 129, 2719-2740, 2003.

Crevoisier, C., Gloor, M., Gloaguen, E., Horowitz, L. W., Sarmiento, J. L., Sweeney, C., and Tans, P. P.: A direct carbon budgeting approach to infer carbon sources and sinks. Design and synthetic application to complement the NACP observation network, Tellus B, 58, 366-375, 2006.
Crevoisier, C., Chédin, A., Matsueda, H., Machida, T., Armante, R., and Scott, N. A.: First year of upper tropospheric integrated content of $\mathrm{CO}_{2}$ from IASI hyperspectral infrared observations, Atmos. Chem. Phys., 9, 4797-4810, https://doi.org/10.5194/acp9-4797-2009, 2009a.

Crevoisier, C., Nobileau, D., Fiore, A. M., Armante, R., Chédin, A., and Scott, N. A.: Tropospheric methane in the tropics - first year from IASI hyperspectral infrared observations, Atmos. Chem. Phys., 9, 6337-6350, https://doi.org/10.5194/acp-9-6337-2009, 2009b.

Crevoisier, C., Sweeney, C., Gloor, M., Sarmiento, J. L., and Tans, P. P.: Regional US carbon sinks from three-dimensional atmospheric $\mathrm{CO}_{2}$ sampling, P. Natl. Acad. Sci. USA, 107, 1834818353, 2010.

Crevoisier, C., Nobileau, D., Armante, R., Crépeau, L., Machida, T., Sawa, Y., Matsueda, H., Schuck, T., Thonat, T., Pernin, J., Scott, N. A., and Chédin, A.: The 2007-2011 evolution of tropical methane in the mid-troposphere as seen from space by MetOp-A/IASI, Atmos. Chem. Phys., 13, 4279-4289, https://doi.org/10.5194/acp-13-4279-2013, 2013.

Crisp, D., Atlas, R. M., Breon, F. M., Brown, L. R., Burrows, J. P., Ciais, P., Connor, B. J., Doney, S. C., Fung, I. Y., Jacob, D. J., Miller, C. E., O’Brien, D., Pawson, S., Randerson, J. T., Rayner, P., Salawitch, R. J., Sander, S. P., Sen, B., Stephens, G. L., Tans, P. P., Toon, G. C., Wennberg, P. O., Wofsy, S. c., Yung, Y. L., Kuang, Z., Chudasama, B., Sprague, G., Weiss, B., Pollock, R., Kenyon, D., and Schroll, S.: The Orbiting Carbon Observatory (OCO) mission, Adv. Space Res., 34, 700-709, 2004.

Crosson, E.: A cavity ring-down analyzer for measuring atmospheric levels of methane, carbon dioxide, and water vapor, Appl Phys. B, 92, 403-408, https://doi.org/10.1007/s00340-008-3135y, 2008.

Durry, G., Amarouche, N., Zeninari, V., Parvitte, B., Lebarbu, T., and Ovarlez, J.: In situ sensing of the middle atmosphere with balloonborne near-infrared laser diodes, Spectrochim. Acta A, 60, 3371-3379, 2004.

Engel, A., Strunk, M., Müller, M., Haase, H.-P., Poss, C., Levin, I., and Schmidt, U.: Temporal development of total chlorine in the high-latitude stratosphere based on reference distributions of mean age derived from $\mathrm{CO}_{2}$ and $\mathrm{SF}_{6}$, J. Geophys. Res.-Atmos., 107, ACH 1-1-ACH 1-11, https://doi.org/10.1029/2001JD000584, 2002.

Engel, A., Möbius, T., Bönisch, H., Schmidt, U., Heinz, R., Levin, I., Atlas, E., Aoki, S., Nakazawa, T., Sugawara, S., Moore, F., Hurst, D., Elkins, J., Schauffler, S., Andrews, A., and Boering, K.: Age of stratospheric air unchanged within uncertainties over the past 30 years, Nat. Geosci., 2, 28-31, 2008.

Foucher, P. Y., Chédin, A., Armante, R., Boone, C., Crevoisier, C., and Bernath, P.: Carbon dioxide atmospheric vertical profiles retrieved from space observation using ACE-FTS solar occultation instrument, Atmos. Chem. Phys., 11, 2455-2470, https://doi.org/10.5194/acp-11-2455-2011, 2011.

Frankenberg, C., Aben, I., Bergamaschi, P., Dlugokencky, E. J., van Hees, R., Houweling, S., van der Meer, P., Snel, R., and Tol, P.: Global column-averaged methane mixing ratios from 2003 to 2009 as derived from SCIAMACHY: Trends and variability, J. Geophys. Res.-Biogeo., 116, D04302, https://doi.org/10.1029/2010JD014849, 2011. 
GCOS: Systematic observation requirements for satellite-based data products for climate, Global Climate Observing System154, avialable at: http://www.wmo.int/pages/prog/gcos/ (last access: 15 October 2016), 2011.

Ghysels, M., Gomez, L., Cousin, J., Amarouche, N., Jost, H., and Durry, G.: Spectroscopy of $\mathrm{CH}_{4}$ with a difference-frequency generation laser at 3.3 micron for atmospheric applications, Appl. Phys. B, 104, 989-1000, 2011.

Hamazaki, T., Kaneko, Y., Kuze, A., and Suto, H.: Greenhouse Gases Observation from Space with TANSO-FTS on GOSAT, Fourier Transform Spectroscopy/ Hyperspectral Imaging and Sounding of the Environment (2007), paper FWB1, p. FWB1, 2007.

Hammerling, D. M., Michalak, A. M., and Kawa, S. R.: Mapping of $\mathrm{CO}_{2}$ at high spatiotemporal resolution using satellite observations: Global distributions from OCO-2, J. Geophys. Res.Biogeo., 117, D06306, https://doi.org/10.1029/2011JD017015, 2012.

Houweling, S., Krol, M., Bergamaschi, P., Frankenberg, C., Dlugokencky, E. J., Morino, I., Notholt, J., Sherlock, V., Wunch, D., Beck, V., Gerbig, C., Chen, H., Kort, E. A., Röckmann, T., and Aben, I.: A multi-year methane inversion using SCIAMACHY, accounting for systematic errors using TCCON measurements, Atmos. Chem. Phys., 14, 3991-4012, https://doi.org/10.5194/acp-14-3991-2014, 2014.

Joly, L., Parvitte, B., Zeninari, V., and Durry, G.: Development of a compact $\mathrm{CO} 2$ sensor open to the atmosphere and based on near-infrared laser technology at $2.68 \mu \mathrm{m}$, Appl. Phys. B, https://doi.org/10.1007/s00340-006-2568-4, 2007.

Karion, A., Sweeney, C., Tans, P., and Newberger, T.: AirCore: An Innovative Atmospheric Sampling System, J. Atmos. Ocean. Technol., 27, 1839-1853, https://doi.org/10.1175/2010JTECHA1448.1, 2010.

Karion, A., Sweeney, C., Pétron, G., Frost, G., Michael Hardesty, R., Kofler, J., Miller, B. R., Newberger, T., Wolter, S., Banta, R., Brewer, A., Dlugokencky, E., Lang, P., Montzka, S. A., Schnell, R., Tans, P., Trainer, M., Zamora, R., and Conley, S.: Methane emissions estimate from airborne measurements over a western United States natural gas field, Geophys. Res. Lett., 40, 43934397, 2013.

Machida, T., Matsueda, H., Sawa, Y., Nakagawa, Y., Hirotani, K., Kondo, N., Goto, K., Nakazawa, T., Ishikawa, K., and Ogawa, T.: Worldwide Measurements of Atmospheric $\mathrm{CO}_{2}$ and Other Trace Gas Species Using Commercial Airlines, J. Atmos. Ocean. Technol., 25, 1744-1754, 2008.

Massart, S., Agusti-Panareda, A., Aben, I., Butz, A., Chevallier, F., Crevoisier, C., Engelen, R., Frankenberg, C., and Hasekamp, O.: Assimilation of atmospheric methane products into the MACCII system: from SCIAMACHY to TANSO and IASI, Atmos. Chem. Phys., 14, 6139-6158, https://doi.org/10.5194/acp-146139-2014, 2014.

Massman, W. J.: A review of the molecular diffusivities of $\mathrm{H}_{2} \mathrm{O}$, $\mathrm{CO}_{2}, \mathrm{CH}_{4}, \mathrm{CO}, \mathrm{O}_{3}, \mathrm{SO}_{2}, \mathrm{NH}_{3}, \mathrm{~N}_{2} \mathrm{O}, \mathrm{NO}$, and $\mathrm{NO}_{2}$ in air, $\mathrm{O}_{2}$ and $\mathrm{N}_{2}$ near STP, Atmos. Environ., 32, 1111-1127, 1998.

Moreau, G., Robert, C., Catoire, V., Chartier, M., Camy-Peyret, C., Huret, N., Pirre, M., Pomathiod, L., and Chalumeau, G.: SPIRALE: a multispecies in situ balloonborne instrument with six tunable diode laser spectrometers, Appl. Opt., 44, 5972-5989, https://doi.org/10.1364/AO.44.005972, 2005.
Oelhaf, H., Clarmann, T. V., Fergg, F., Fischer, H., Friedl-Vallon, F., Fritzsche, C., Piesch, C., Rabus, D., Seefeldner, M., and Voelker, W.: Remote sensing of trace gases with a balloon borne version of the Michelson Interferometer for Passive Atmospheric Sounding (MIPAS), ESA Special Publication, 317, 207-213, 1991.

Peixinho, J. and Mullin, T.: Decay of Turbulence in Pipe Flow, Phys. Rev. Lett., 96, 094501, https://doi.org/10.1103/PhysRevLett.96.094501, 2006.

Reichler, T., Dameris, M., and Sausen, R.: Determination of tropopause heights from gridded data, Geophys. Res. Lett, 30, 20, https://doi.org/10.1029/2003GL018240, 2003.

Rella, C. W., Chen, H., Andrews, A. E., Filges, A., Gerbig, C., Hatakka, J., Karion, A., Miles, N. L., Richardson, S. J., Steinbacher, M., Sweeney, C., Wastine, B., and Zellweger, C.: High accuracy measurements of dry mole fractions of carbon dioxide and methane in humid air, Atmos. Meas. Tech., 6, 837-860, https://doi.org/10.5194/amt-6-837-2013, 2013.

Reynolds, O.: An Experimental Investigation of the Circumstances Which Determine Whether the Motion of Water Shall Be Direct or Sinuous, and of the Law of Resistance in Parallel Channels, Philos. T. R. Soc. Lond., 174, 935-982, https://doi.org/10.1098/rspl.1883.0018, 1883.

Schmidt, U. and Khedim, A.: In situ measurements of carbon dioxide in the winter Arctic vortex and at midlatitudes: An indicator of the "age" of stratopheric air, Geophys. Res. Lett., 18, 763-766, 1991.

Schuck, T. J., Brenninkmeijer, C. A. M., Slemr, F., Xueref-Remy, I., and Zahn, A.: Greenhouse gas analysis of air samples collected onboard the CARIBIC passenger aircraft, Atmos. Meas. Tech., 2, 449-464, https://doi.org/10.5194/amt-2-449-2009, 2009.

Stowasser, C., Farinas, A. D., Ware, J., Wistisen, D. W., Rella, C., Wahl, E., Crosson, E., and Blunier, T.: A low-volume cavity ring-down spectrometer for sample-limited applications, Appl. Phys. B, 116, 255-270, https://doi.org/10.1007/s00340013-5528-9, 2014.

Sweeney, C., Karion, A., Wolter, S., Newberger, T., Guenther, D., Higgs, J. A., Andrews, A. E., Lang, P. M., Neff, D., Dlugokencky, E., Miller, J. B., Montzka, S. A., Miller, B. R., Masarie, K. A., Biraud, S. C., Novelli, P. C., Crotwell, M., Crotwell, A. M., Thoning, K., and Tans, P. P.: Seasonal climatology of $\mathrm{CO}_{2}$ across North America from aircraft measurements in the NOAA/ESRL Global Greenhouse Gas Reference Network, J. Geophys. Res.Atmos., 120, 5155-5190, 2015.

Tans, P. P.: System and method for providing vertical profile measurements of atmospheric gases, US Patent Office, 2009.

Verma, S., Marshall, J., Parrington, M., Agusti-Panareda, A., Massart, S., Chipperfield, M. P., Wilson, C., and Gerbig, C.: Extending methane profiles from aircraft into the stratosphere for satellite total column validation: A comparative analysis of different data sources, Atmos. Chem. Phys. Discuss., https://doi.org/10.5194/acp-2016-704, in review, 2016.

Wecht, K. J., Jacob, D. J., Frankenberg, C., Jiang, Z., and Blake, D. R.: Mapping of North American methane emissions with high spatial resolution by inversion of SCIAMACHY satellite data, J. Geophys. Res.-Atmos., 119, 7741-7756, 2014.

Wofsy, S. c.: HIAPER Pole-to-Pole Observations (HIPPO): finegrained, global-scale measurements of climatically important atmospheric gases and aerosols, Philosophical Transactions of the 
Royal Society of London A: Mathematical, Phys. Eng. Sci., 369, 2073-2086, 2011.

Worden, J., Kulawik, S., Frankenberg, C., Payne, V., Bowman, K., Cady-Peirara, K., Wecht, K., Lee, J.-E., and Noone, D.: Profiles of $\mathrm{CH}_{4}, \mathrm{HDO}, \mathrm{H}_{2} \mathrm{O}$, and $\mathrm{N}_{2} \mathrm{O}$ with improved lower tropospheric vertical resolution from Aura TES radiances, Atmos. Meas. Tech., 5, 397-411, https://doi.org/10.5194/amt-5397-2012, 2012.

Wunch, D., Toon, G. C., Wennberg, P. O., Wofsy, S. C., Stephens, B. B., Fischer, M. L., Uchino, O., Abshire, J. B., Bernath, P., Biraud, S. C., Blavier, J.-F. L., Boone, C., Bowman, K. P., Browell, E. V., Campos, T., Connor, B. J., Daube, B. C., Deutscher, N. M., Diao, M., Elkins, J. W., Gerbig, C., Gottlieb, E., Griffith, D. W. T., Hurst, D. F., Jiménez, R., Keppel-Aleks, G., Kort, E. A., Macatangay, R., Machida, T., Matsueda, H., Moore, F., Morino, I., Park, S., Robinson, J., Roehl, C. M., Sawa, Y., Sherlock, V., Sweeney, C., Tanaka, T., and Zondlo, M. A.: Calibration of the Total Carbon Column Observing Network using aircraft profile data, Atmos. Meas. Tech., 3, 1351-1362, https://doi.org/10.5194/amt-3-1351-2010, 2010.
Xiong, X., Barnet, C., Maddy, E., Wei, J., Liu, X., and Pagano, T. S.: Seven Years Observation of Mid-Upper Tropospheric Methane from Atmospheric Infrared Sounder, Remote Sensing, 2, 25092530, 2010.

Xiong, X., Barnet, C., Maddy, E. S., Gambacorta, A., King, T. S., and Wofsy, S. C.: Mid-upper tropospheric methane retrieval from IASI and its validation, Atmos. Meas. Tech., 6, 2255-2265, https://doi.org/10.5194/amt-6-2255-2013, 2013.

Zhang, H. F., Chen, B. Z., van der Laan-Luijk, I. T., Machida, T., Matsueda, H., Sawa, Y., Fukuyama, Y., Langenfelds, R., van der Schoot, M., Xu, G., Yan, J. W., Cheng, M. L., Zhou, L. X., Tans, P. P., and Peters, W.: Estimating Asian terrestrial carbon fluxes from CONTRAIL aircraft and surface $\mathrm{CO} 2$ observations for the period 2006-2010, Atmos. Chem. Phys., 14, 5807-5824, https://doi.org/10.5194/acp-14-5807-2014, 2014. 